\title{
Magnetic anomalies of the mafic/ultramafic Seiland Igneous Province
}

\author{
Zeudia Pastore', Christine Fichler' \& Suzanne A. McEnroe' \\ ${ }^{1}$ Department of Geoscience and Petroleum at the Norwegian University of Science and Technology (NTNU) Trondheim, Norway. \\ E-mail corresponding author (Zeudia Pastore): zeudia.pastore@ntnu.no
}

The Ediacaran Seiland Igneous Province (SIP) is the largest complex of mafic-ultramafic intrusions in northern Fennoscandia and one of the few examples of a well preserved deep-seated magmatic plumbing system. The major gravity anomaly caused by the dense rocks of the SIP has been recently modelled indicating multiple deep roots located north of the Øksfjord peninsula. Magnetic forward modelling is applied to estimate the geometry and the magnetisation of the magnetic sources. The largest magnetic anomaly is located at the eastern side of the Øksfjord peninsula and far from the deep ultramafic roots of the complex. The modelled sources of the magnetic anomalies reach a maximum depth of $3 \mathrm{~km}$ and are related both to gabbroic bodies and to a lesser extent to the contacts of the ultramafic intrusions with country rock. Rock properties were analysed using the petrophysical database of the Geological Survey of Norway. Generally, SIP rocks have low natural remanent magnetisations (NRM) and Königsberger ratios (Q) below 2. However, high NRM values are observed at the eastern side of the Øksfjord peninsula, where the NRM direction will strongly affect the magnetic anomalies and the modelling results. Due to the lack of NRM directional information, we modelled the effect of different NRM directions. Comparison with the magnetic anomalies indicated steep NRM inclinations. Most of the ultramafic rocks have high densities and low susceptibilities, with a few exceptions on the island of Seiland where tectonic processes and later alteration likely affected the magnetic properties. Modelling suggests the alteration at these locations is within a depth of $400 \mathrm{~m}$. The occurrence of numerous metal deposits on the island of Stjernøya, and particularly around one of the roots of the SIP, suggests that the root could have acted as a preferential pathway for the fluids accommodating the precipitation of metal-bearing minerals.

Keywords: 3D magnetic modeling, Natural Remanent Magnetisation, magnetic gabbros, ultramafic roots, metal deposits

Received 29. September 2017 / Accepted 12. March 2018 / Published online 30. April 2018

\section{Introduction and geological setting}

Large ultramafic - mafic intrusions are rare in the geological time record and are of great interest because they are commonly associated with economically valuable deposits of natural resources (Ernst, 2007). The Seiland Igneous Province (SIP) is the largest complex of mafic and ultramafic intrusions in northern Fennoscandia (Fig. 1). The SIP, exposed in the Middle Allochthon of the Norwegian Caledonides, has been suggested by previous studies to represent the massive plumbing system of deep-seated (25-30 km depth) magmatic conduits (Grant et al., 2016; Larsen et al., 2018).
The SIP is exposed on the islands of Seiland, Sørøya, Stjernøya, and on the Øksfjord peninsula in northern Finnmark (Fig. 1). The intrusive complex consists of numerous, commonly layered mafic plutons, which constitute at least $60 \%$ of the area. Large ultramafic complexes comprise about 25\%, intermediate rock types such as monzonite and diorite about $10 \%$, and calc-alkaline and younger alkaline igneous plutons about $5 \%$. The volumetrically largest part of the SIP has been emplaced within a short time span of about 10 Ma, between 570-560 Ma (Roberts et al., 2006, 2010). Despite the fact that the SIP intrusions have been emplaced over a short time span, the compositions of intrusions are quite variable across the complex, due to fractional crystallisation processes and crustal 


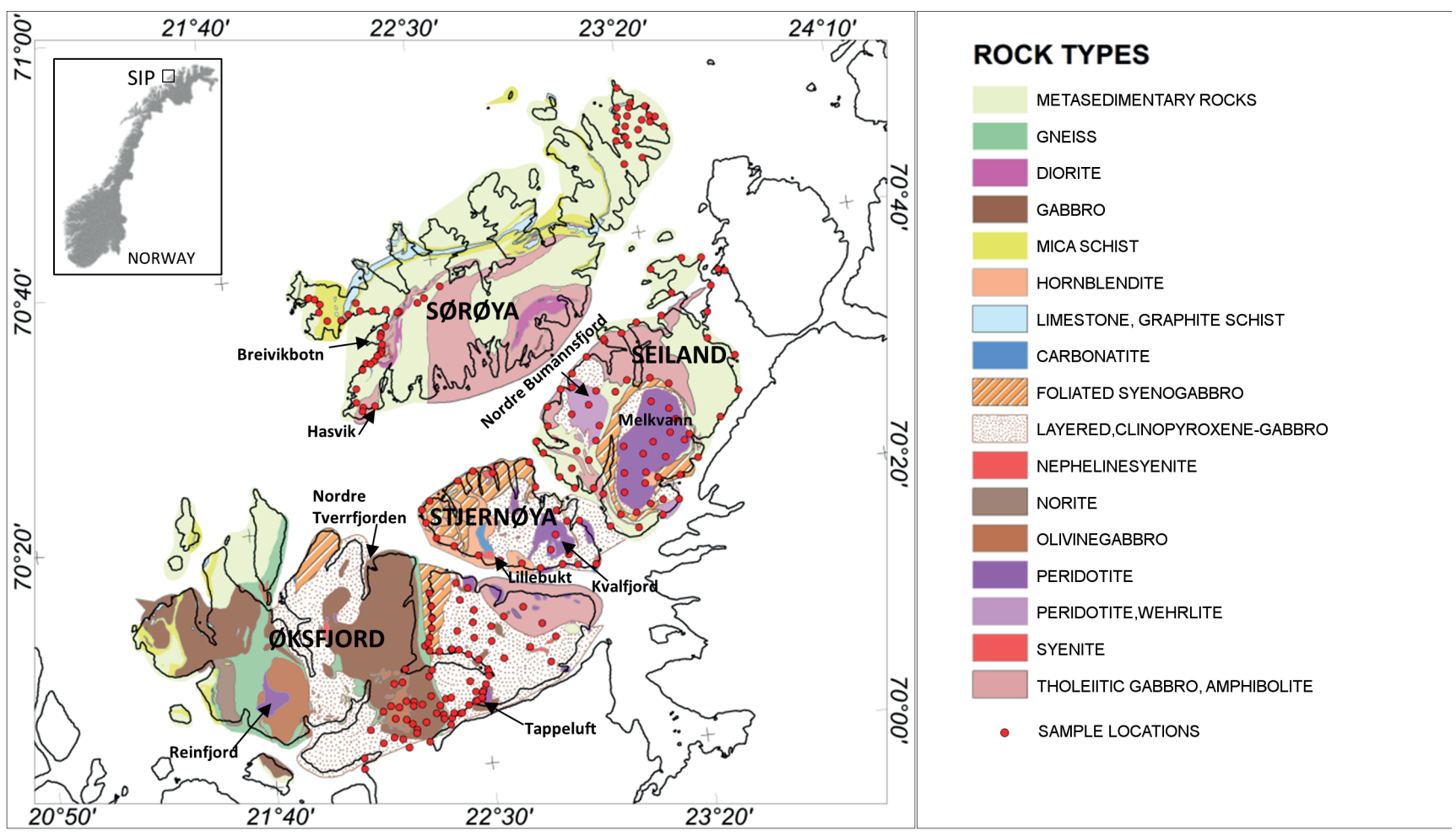

Figure 1. Modified geological map (Geological Survey of Norway: scale 1:250,000, http://geo.ngu.no/kart/kartkatalog/) with main localities discussed in the text and sample locations (red dots).

contamination (Roberts, 2007). This variability would be expected to be reflected in the magnetic properties (magnetic susceptibilities and remanent magnetisation) and response of the rock bodies. The igneous rocks of the SIP generally show higher magnetic susceptibilities than the metasedimentary host rocks (Table 1); and whereas magnetic anomalies can be correlated to the SIP rocks, the surrounding metasedimentary rocks have a very weak magnetic signal (Fig. 2A). This distinction is observed also in the low-pass filtered map of the magnetic field anomalies obtained using a cutoff wavelength of $20 \mathrm{~km}$. Here, a ring-shaped magnetic low bounds and separates the SIP rocks from the host rocks (Fig. 2D). Magnetic anomalies reflect the magnetic mineral distribution and therefore provide a powerful tool for the mapping of petrological changes. Here, we focus on the SIP magnetic anomalies with an aim to infer lithological units at and below the surface, distinguishing between mafic and ultramafic intrusions, identifying the prospective potential for ores and mineral deposits, and improving the understanding of the processes responsible for the magnetic anomalies. Robins (1985) described large, subeconomic deposits of $\mathrm{Fe}$-Ti oxides within the Seiland igneous Province, which are associated with layered mafic intrusions and alkaline ultrabasic rocks. The occurrence of these oxides will strongly affect the magnetic properties of the rocks and will therefore be reflected in the magnetic anomalies.
The pronounced gravity anomalies of the SIP (cf., Brooks, 1970) were recently interpreted by gravity modelling (Pastore et al., 2016) resulting in the overall shape of the large magmatic body. This work showed the presence of two deep-reaching roots and estimated the minimum volume of the SIP to be $17,000 \mathrm{~km}^{3}$. Fig. $2 \mathrm{E}$, F show the Bouguer gravity anomaly and the base of the SIP (Pastore et al., 2016).

\section{Aeromagnetic data}

The new high-resolution aeromagnetic data compilation (TROFI-14; Olesen et al., 2010; Nasuti et al., 2015) provided by the Geological Survey of Norway was used to investigate the study area (Fig. 2A). Map processing was performed in GEOSOFT Oasis Montaj. The aeromagnetic resolution for the entire study area is not uniform and is thus highly dependent of the flight-line spacing which varies between 200 (over the mainland) and $2000 \mathrm{~m}$ (continental shelf), with tie-line spacing varying from 2000 to $10,000 \mathrm{~m}$. During the acquisition, the sensor altitude adopted a nominal drape flying altitude between 60 and $200 \mathrm{~m}$. The data cover both onshore and offshore areas of the SIP. Including the modelling of the inaccessible offshore areas will allow 
Table 1. Statistics on NGU's petrophysical database.

\begin{tabular}{|c|c|c|c|c|c|c|c|c|c|c|c|c|}
\hline \multirow[b]{2}{*}{$\operatorname{DENSITY}\left(\mathrm{kg} / \mathrm{m}^{3}\right)$} & \multicolumn{3}{|c|}{ GABBROS } & \multicolumn{3}{|c|}{$U M$} & \multicolumn{3}{|c|}{$\begin{array}{c}\text { ALKALINE/ } \\
\text { CARBONATITE }\end{array}$} & \multicolumn{3}{|c|}{$\begin{array}{c}\text { METASEDIMENTARY } \\
\text { ROCKS }\end{array}$} \\
\hline & $A L L(118)$ & $d \_A(66)$ & $d \_B(52)$ & $A L L(30)$ & $d \_A(25)$ & $d \_B(5)$ & $A L L(15)$ & $d \_A(5)$ & $d \_B(10)$ & $A L L(103)$ & $d \_A(98)$ & $d \_B(5)$ \\
\hline Max. & 3400 & 3319 & 3400 & 3438 & 3438 & 3345 & 2966 & 2966 & 2965 & 3122 & 3122 & 2980 \\
\hline Min. & 2637 & 2637 & 2769 & 2919 & 2919 & 3055 & 2593 & 2593 & 2624 & 2585 & 2612 & 2585 \\
\hline Median (black line) & 3046 & 3031 & 3073 & 3222 & 3222 & 3180 & 2687 & 2672 & 2705 & 2761 & 2761 & 2700 \\
\hline $25 \%$ & 2968 & 2988 & 2946 & 3130 & 3162 & 3064 & 2663 & 2604 & 2665 & 2700 & 2702 & 2599 \\
\hline $75 \%$ & 3147 & 3134 & 3164 & 3311 & 3306 & 3342 & 2834 & 2836 & 2858 & 2830 & 2828 & 2909 \\
\hline Mean (red line) & 3053 & 3040 & 3069 & 3215 & 3219 & 3198 & 2743 & 2710 & 2759 & 2778 & 2780 & 2743 \\
\hline Std. dev & 142 & 130 & 157 & 124 & 123 & 140 & 128 & 150 & 121 & 112 & 110 & 165 \\
\hline Std. error & 13 & 16 & 22 & 23 & 25 & 62 & 33 & 67 & 38 & 11 & 11 & 74 \\
\hline SUSCEPTIBILITY (SI) & $A L L$ & $k \_A$ & $k \_B$ & $A L L$ & $k \_A$ & $k \_B$ & $A L L$ & $k \_A$ & $k \_B$ & $A L L$ & $k \_A$ & $k \_B$ \\
\hline Max. & 0.2460 & 0.1480 & 0.2460 & 0.0689 & 0.0689 & 0.0316 & 0.0895 & 0.0271 & 0.0895 & 0.0574 & 0.0565 & 0.0574 \\
\hline Min. & 0.0004 & 0.0006 & 0.0004 & 0.0003 & 0.0003 & 0.0022 & 0.0004 & 0.0004 & 0.0006 & 0.0000 & 0.0000 & 0.0004 \\
\hline Median & 0.0072 & 0.0032 & 0.0273 & 0.0053 & 0.0049 & 0.0099 & 0.0105 & 0.0006 & 0.0181 & 0.0003 & 0.0003 & 0.0024 \\
\hline $25 \%$ & 0.0017 & 0.0013 & 0.0049 & 0.0026 & 0.0026 & 0.0037 & 0.0006 & 0.0005 & 0.0016 & 0.0002 & 0.0002 & 0.0009 \\
\hline $75 \%$ & 0.0315 & 0.0085 & 0.0612 & 0.0105 & 0.0099 & 0.0266 & 0.0288 & 0.0209 & 0.0389 & 0.0005 & 0.0005 & 0.0343 \\
\hline Mean & 0.0251 & 0.0106 & 0.0436 & 0.0106 & 0.0100 & 0.0141 & 0.0198 & 0.0087 & 0.0253 & 0.0025 & 0.0018 & 0.0146 \\
\hline Std. dev & 0.0412 & 0.0224 & 0.0513 & 0.0143 & 0.0148 & 0.0123 & 0.0259 & 0.0120 & 0.0296 & 0.0094 & 0.0078 & 0.0243 \\
\hline Std. error & 0.0038 & 0.0028 & 0.0071 & 0.0026 & 0.0030 & 0.0055 & 0.0067 & 0.0054 & 0.0094 & 0.0009 & 0.0008 & 0.0109 \\
\hline$Q$ & $A L L$ & $Q \_A$ & $Q \_B$ & $A L L$ & $Q \_A$ & $Q \_B$ & $A L L$ & Q_A & Q_B & $A L L$ & $Q \_A$ & $Q \_B$ \\
\hline Max. & 135.4 & 135.4 & 9.1 & 45.2 & 45.2 & 13.6 & 1.3 & 0.9 & 1.3 & 16.1 & 16.1 & 1.9 \\
\hline Min. & 0.1 & 0.1 & 0.1 & 0.3 & 0.3 & 0.5 & 0.1 & 0.2 & 0.1 & 0.1 & 0.1 & 0.4 \\
\hline Median & 0.9 & 0.9 & 0.8 & 1.6 & 1.6 & 1.0 & 0.6 & 0.7 & 0.6 & 1.0 & 1.0 & 1.0 \\
\hline $25 \%$ & 0.4 & 0.4 & 0.4 & 0.9 & 1.2 & 0.5 & 0.2 & 0.2 & 0.2 & 0.5 & 0.5 & 0.4 \\
\hline $75 \%$ & 1.6 & 1.6 & 1.6 & 4.2 & 4.4 & 7.4 & 0.9 & 0.9 & 0.8 & 1.9 & 1.9 & 1.7 \\
\hline Mean & 2.8 & 3.9 & 1.5 & 4.2 & 4.4 & 3.3 & 0.6 & 0.6 & 0.6 & 1.6 & 1.7 & 1.0 \\
\hline Std. dev & 12.7 & 17.0 & 1.9 & 8.4 & 9.0 & 5.7 & 0.4 & 0.4 & 0.4 & 2.3 & 2.4 & 0.7 \\
\hline Std. error & 1.2 & 2.1 & 0.3 & 1.6 & 1.8 & 2.6 & 0.1 & 0.2 & 0.1 & 0.3 & 0.3 & 0.3 \\
\hline$N R M(A / m)$ & $A L L$ & $N R M \_A$ & $N R M \_B$ & $A L L$ & $N R M \_A$ & $N R M \_B$ & $A L L$ & $N R M \_A$ & $N R M \_B$ & $A L L$ & $N R M \_A$ & NRM_B \\
\hline Max. & 13.82 & 7.21 & 13.82 & 4.22 & 4.21 & 2.98 & 3.42 & 0.18 & 3.42 & 2.26 & 2.26 & 0.92 \\
\hline Min. & 0.00 & 0.01 & 0.01 & 0.03 & 0.03 & 0.11 & 0.02 & 0.02 & 0.02 & 0.00 & 0.01 & 0.03 \\
\hline Median & 0.29 & 0.17 & 0.93 & 0.40 & 0.36 & 0.42 & 0.15 & 0.02 & 0.18 & 0.01 & 0.01 & 0.10 \\
\hline $25 \%$ & 0.09 & 0.06 & 0.28 & 0.11 & 0.10 & 0.26 & 0.03 & 0.02 & 0.04 & 0.01 & 0.01 & 0.06 \\
\hline $75 \%$ & 1.13 & 0.39 & 1.96 & 1.78 & 1.97 & 1.92 & 0.31 & 0.18 & 0.60 & 0.03 & 0.02 & 0.56 \\
\hline Mean & 1.08 & 0.55 & 1.74 & 1.06 & 1.08 & 0.95 & 0.47 & 0.07 & 0.59 & 0.08 & 0.08 & 0.27 \\
\hline Std. dev & 2.01 & 1.19 & 2.57 & 1.35 & 1.40 & 1.16 & 0.95 & 0.09 & 1.06 & 0.28 & 0.28 & 0.37 \\
\hline Std. error & 0.19 & 0.15 & 0.36 & 0.25 & 0.29 & 0.52 & 0.26 & 0.05 & 0.34 & 0.03 & 0.03 & 0.17 \\
\hline
\end{tabular}

for a more complete interpretation of the SIP. The data, corrected for the IGRF field using the 2010 model (EON Geosciences Inc., 2015), have been gridded with minimum curvature and grid cell size of $250 \mathrm{~m}$. The magnetic anomalies have magnitudes from -716 nT (offshore at Øksfjord) up to $2356 \mathrm{nT}$; the aeromagnetic data over the SIP show several positive magnetic anomalies which due to their small wavelengths are restricted to minor, shallow bodies.
A first comparison of the magnetic anomalies map with the elevation map (Fig. 2B) reveals that there is some correlation with the topography as seen from the anomalies on the island of Seiland where the magnetic high is truncated at the slope of the topographic high; however, many areas are clearly without correlation as, e.g., offshore, to the south of the island of Sørøya (see Fig. $1)$. 

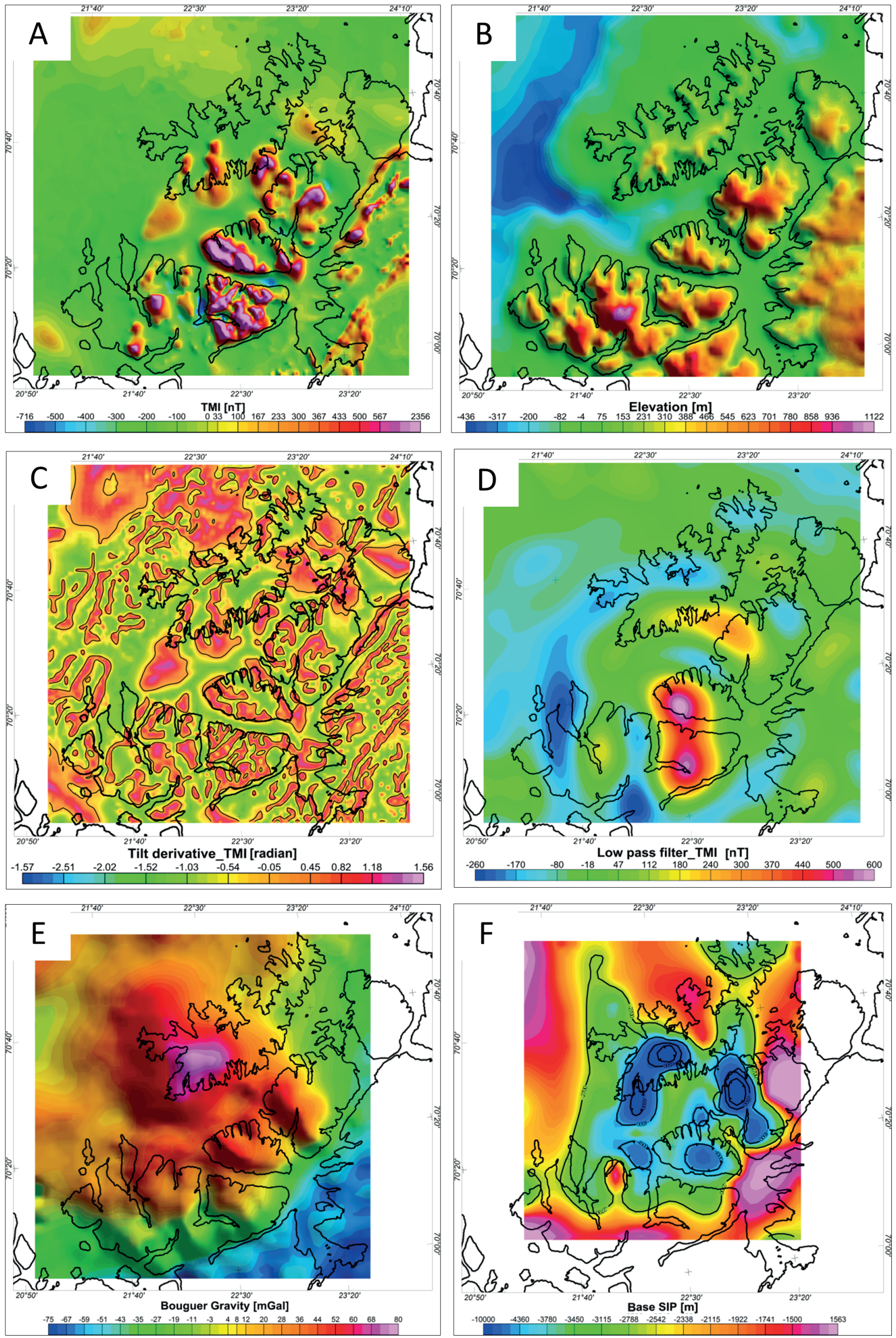

Figure 2. (A) Aeromagnetic map (Geological Survey of Norway; Olesen et al., 2010; Nasuti et al., 2015). (B) Elevation grid (http://kartverket. no/en/Maps--Nautical-Charts/Gratis-kartdata/Open-and-Free-geospatial-data-from-Norway). (C) Tilt-derivative map of the magnetic data. (D) Low-pass filtered map of the magnetic data. (E) Bouguer gravity anomaly map (NGU and GETECH TRIDENT satellite data, compiled by Pastore et al., 2016). (F) Base of the SIP (Pastore et al., 2016). 
A detailed description of the magnetic anomalies by location (Fig. 1) is given below:

Sørøya: the magnetic anomalies in this area correlate with the outcropping gabbroic rocks and continue offshore towards the south for approximatively $10 \mathrm{~km}$. This correlation is enhanced by using the tilt derivative (TDR) map of the magnetic anomalies (Fig. 2C), especially clear in the westernmost part of Sørøya.

Øksfjord: the peninsula shows a high concentration of small-wavelength anomalies (between 1 and $3 \mathrm{~km}$ wavelength) on its eastern side and a few, isolated, distinct magnetic anomalies in the central part (Fig. 2A, C). Particularly, two high-magnetic anomalies border the Reinfjord ultramafic complex to the north and to the east. One clear positive anomaly is located southeast of Nordre Tverrfjorden, correlating with a syenite (Fig. 1).

Stjernøya: the island has three highly magnetic areas; the southern part shows a series of short-wavelength anomalies (between 0.5 and $2 \mathrm{~km}$ wavelength) at the boundary of the syenite/carbonatite complex; in the northern part, at the coastal border of the island, a positive magnetic anomaly is found associated with the foliated syenogabbro; another area with magnetic highs is observed along the eastern coast of the island in association with the gabbros surrounding the ultramafic rocks of the Kvalfjord complex.

Seiland: the magnetic anomalies are located around the ultramafic intrusions similarly to what is observed for the Reinfjord Ultramafic Complex (southern part of Øksfjord peninsula).

\section{Petrophysical data: magnetic susceptibility and density}

For the petrophysical data over the study area we used the Geological Survey of Norway (NGU) petrophysical database (Olesen et al., 2010). The location of the samples is shown in Fig. 1 together with the geological map. Fig. $3 \mathrm{~A}$ shows the magnetic map of the area together with the sampled susceptibility and lithology. A total of 266 samples were grouped into four different lithologies: gabbros, ultramafic rocks, alkaline/carbonatitic rocks and metasedimentary rocks. 148 samples are from mafic and ultramafic rocks and show high susceptibilities compared to the surrounding rocks in northern Finnmark. The mafic and ultramafic rocks are characterised by average susceptibilities of 0.02 SI and 0.01 SI, respectively (Table 1 ; Fig. 3D). The standard deviation on these values is large due to the strong variability within the magmatic complex.

Based on differences in the magnetic anomalies' amplitude and wavelength, two areas have been identified and are marked in Fig. 3A by the letters A (outside the dotted line) and B (within the dotted line). Area A covers the eastern side of Øksfjord, the islands of Sørøya and Seiland and the northern part of the island of Stjernøya. Area B covers the eastern part of the Øksfjord peninsula and the southern part of Stjernøya. Fig. 3D shows three box plots for each of the selected lithological units; the first box plot is based on all data for the analysed lithology, while the other two are based on the data from area A or B. The box plots show that the medians (black segments) and average susceptibilities (red segments) are higher in area B; at this location the amplitude of the magnetic anomalies is also higher. However, the distribution of the magnetic susceptibility in each area is not homogeneous; in the area $\mathrm{A}$ at the northern side of the Melkvann ultramafic complex on Seiland, several samples including both gabbros and peridotites show susceptibilities higher than 0.02 SI and densities below the respective averages (Fig. 3B, C; Table 1). This causes a large deviation of the average susceptibility from the median value in the gabbro's box plot from the area A. The deviation of the average susceptibility from the median in the carbonatite/alkaline rocks box plots from area $\mathrm{A}$, and in the metasedimentary rocks box plot from area $\mathrm{B}$ is also relatively large. However, these statistics are based on only a few samples and are not regarded as valid for larger areas.

The susceptibilities for the SIP intrusions vary from a minimum of 0.0003 SI for a peridotite sample, to a maximum of 0.2463 SI for a gabbro sample (Fig. 3). This high magnetic susceptibility would imply a very large magnetite content $(v)$ of c. 7\%, applying the formula of $v[\%]=$ magnetic susceptibility [SI] / 0.0347[SI] (Clark, 1997). Mafic and ultramafic rock densities are quite variable with values ranging from 2637 to $3438 \mathrm{~kg} /$ $\mathrm{m}^{3}$. Some gabbros show notably high densities with values between 3200 and $3400 \mathrm{~kg} / \mathrm{m}^{3}$. These density values are uncommon for gabbroic rocks (2850-3120 $\mathrm{kg} / \mathrm{m}^{3}$; Daly et al., 1966), but more typical for highgrade metamorphic rocks such as eclogites. The density of the gabbros is mainly controlled by the amount of plagioclase vs. mafic minerals, although an increase in magnetite content could also increase the density. In general, based on the magnetic susceptibility values, the high-density gabbros have magnetite contents below $2 \%$; this amount is not enough to increase density up to the value of $3400 \mathrm{~kg} / \mathrm{m}^{3}$. One reason for these density values could be that some gabbros contain a variable amount of mineralisation, which is paramagnetic, therefore adding to the density but not to the magnetic susceptibility. Particularly high natural remanent magnetisations (NRMs) for low magnetite contents may indicate the presence of pyrrhotite, or fine-grained magnetite. The susceptibilities of the ultramafic (UM) rocks vary from 0.0003 to 0.0689 SI. There is a trend indicating that the less dense UM rocks show higher susceptibilities (Fig. 4), possibly due to serpentinisation reactions forming magnetite. This process could explain the locally 

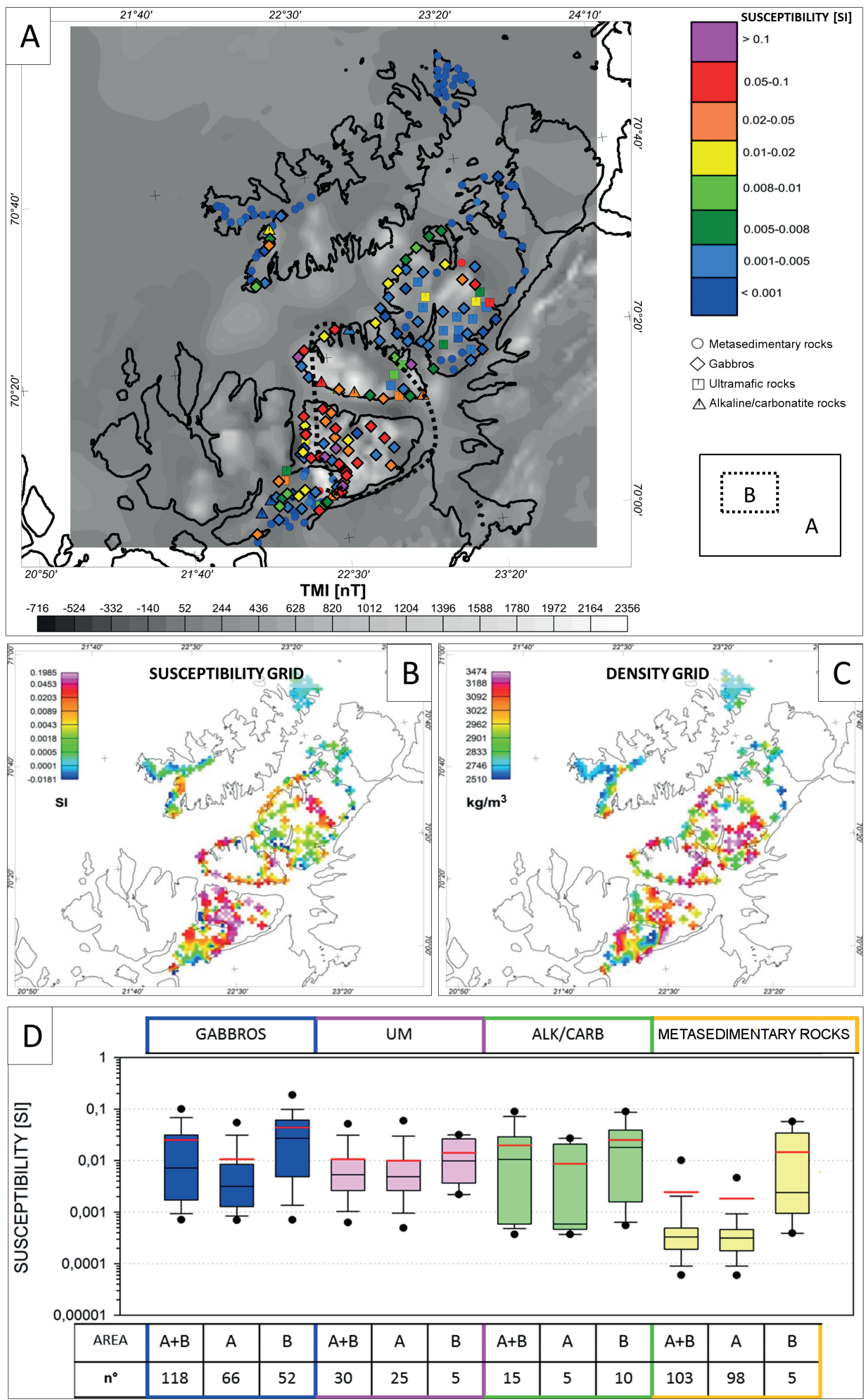

Figure 3. (A) Magnetic anomalies map (grey-scale image) with sample susceptibilities (Olesen et al., 2010). (B) Susceptibility grid. (C) Density grid. (D) Susceptibility box plots with median (black segment), mean (red segment) and 5th and 95th percentiles (black dots). 
occurring high susceptibilities in area A. The magnetic susceptibility values of the gabbros are between 0.0004 and $0.246 \mathrm{SI}$ and are strongly variable throughout the magmatic province; however, there is no clear correlation between the susceptibility and the densities values.

Fig. 5 shows the frequency distribution of the susceptibilities for the selected lithological units. Samples from areas $\mathrm{A}$ and $\mathrm{B}$ are identified by different colours and texture of the columns. The magnetic susceptibility values vary within three orders of magnitude. In order to highlight the most representative values, each plot combines three bin-sized histograms: the bin size is $10^{-4}$ for susceptibility values below $0.001 \mathrm{SI}, 10^{-3}$ for susceptibility values between 0.001 and $0.01 \mathrm{SI}$ and $10^{-2}$ for values above $0.01 \mathrm{SI}$ as annotated on the $\mathrm{x}$-axis of the histograms. The histogram of the metasedimentary rocks is dominated by samples from area $\mathrm{A}$, with a distribution skewed to the left with a large number of occurrences at low susceptibility values. The other lithologies show more complex distributions. In particular, gabbros and UM rocks show a bimodal distribution which in the gabbros correlates with the location of the samples: the majority of the samples from area B plot towards higher susceptibility values compared with area $\mathrm{A}$. The distribution of the alkaline and carbonatite rocks shows a bimodal distribution; however, due to the low number of samples, this is regarded as uncertain. Several modes can be identified in the histograms for each rock type (Fig. 5). Based on these data we selected a set of susceptibility values for modelling the magnetic source bodies. We selected a susceptibility of 0.0002 SI for the host rock based on the metasedimentary rock values, and six different susceptibility values for the intrusive rocks of the SIP.

We used $0.001 \mathrm{SI}$ as a minimum susceptibility value or background magnetic susceptibility for the intrusive rocks of the SIP. This value was used for the modelling of gabbros, UM and alkaline/carbonatite rocks cropping out in areas of weak magnetic field anomaly and for modelling of deeper areas of the SIP interpreted as weakly magnetic. Susceptibility values of 0.003 and 0.009 SI were used to model the UM rocks of the SIP cropping out on the island of Seiland. Large areas of outcropping gabbros were modelled by susceptibility values of either 0.02 or $0.06 \mathrm{SI}$ according to the petrophysical data and the geographical distribution of the samples; gabbros from area B (Fig. 3A) were indeed modelled with a susceptibility of 0.06 SI. Locally in the southeastern part of the SIP, gabbros and alkaline/carbonatite rocks were also modelled with a susceptibility value of $0.1 \mathrm{SI}$.

The highest mode values frequently occur in the samples collected on Stjernøya and the Øksfjord peninsula. Here, Robins (1985) reported significant concentrations of FeTi oxides in the Lillebukt alkaline complex on Stjernøya in connection with the hornblende clinopyroxenite dykes (20\% vol. Fe-Ti oxides: titanomagnetite and ilmenite) and fenites (10\% vol. Fe-Ti oxides: magnetite). Therefore, we consider it reasonable to assume that a high content of ferromagnetic minerals (iron oxides or sulphides) contributes to the very high susceptibilities and densities.

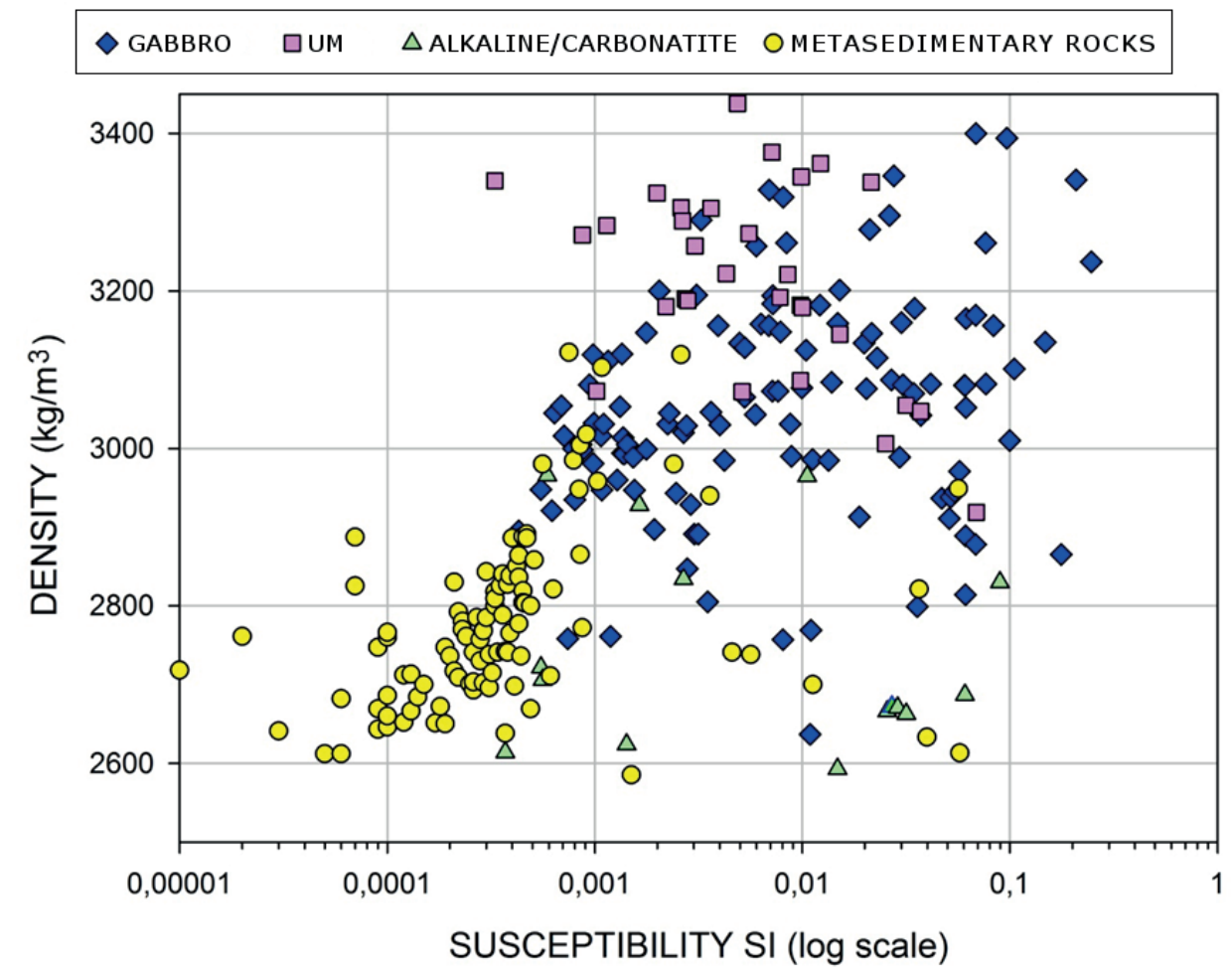

Figure 4. Susceptibility vs. density plot. 


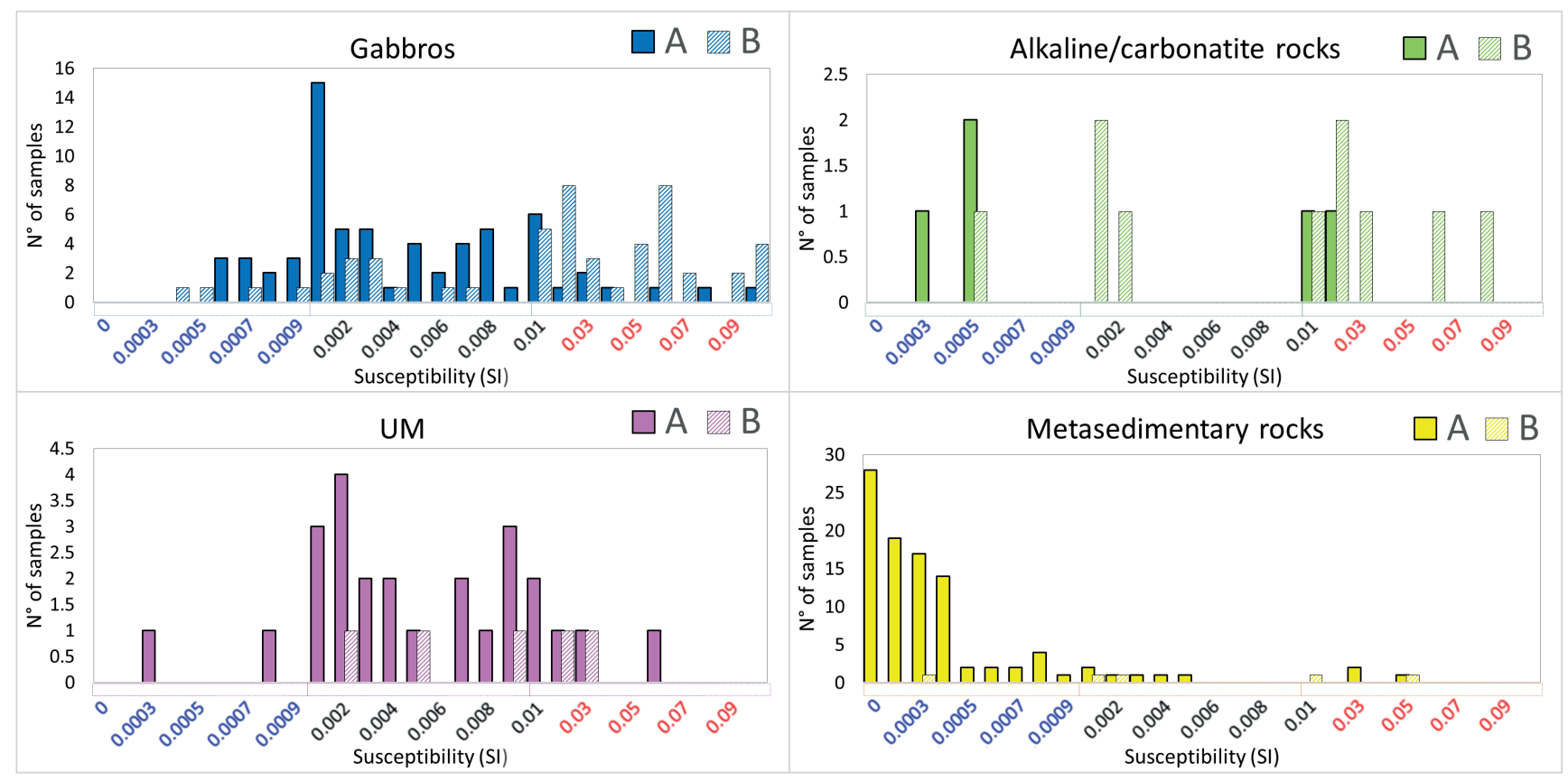

Figure 5. Histograms of susceptibility by areas (A and B) and rock type. On the x-axis of each histograms different bin sizes are highlighted by different font colours.
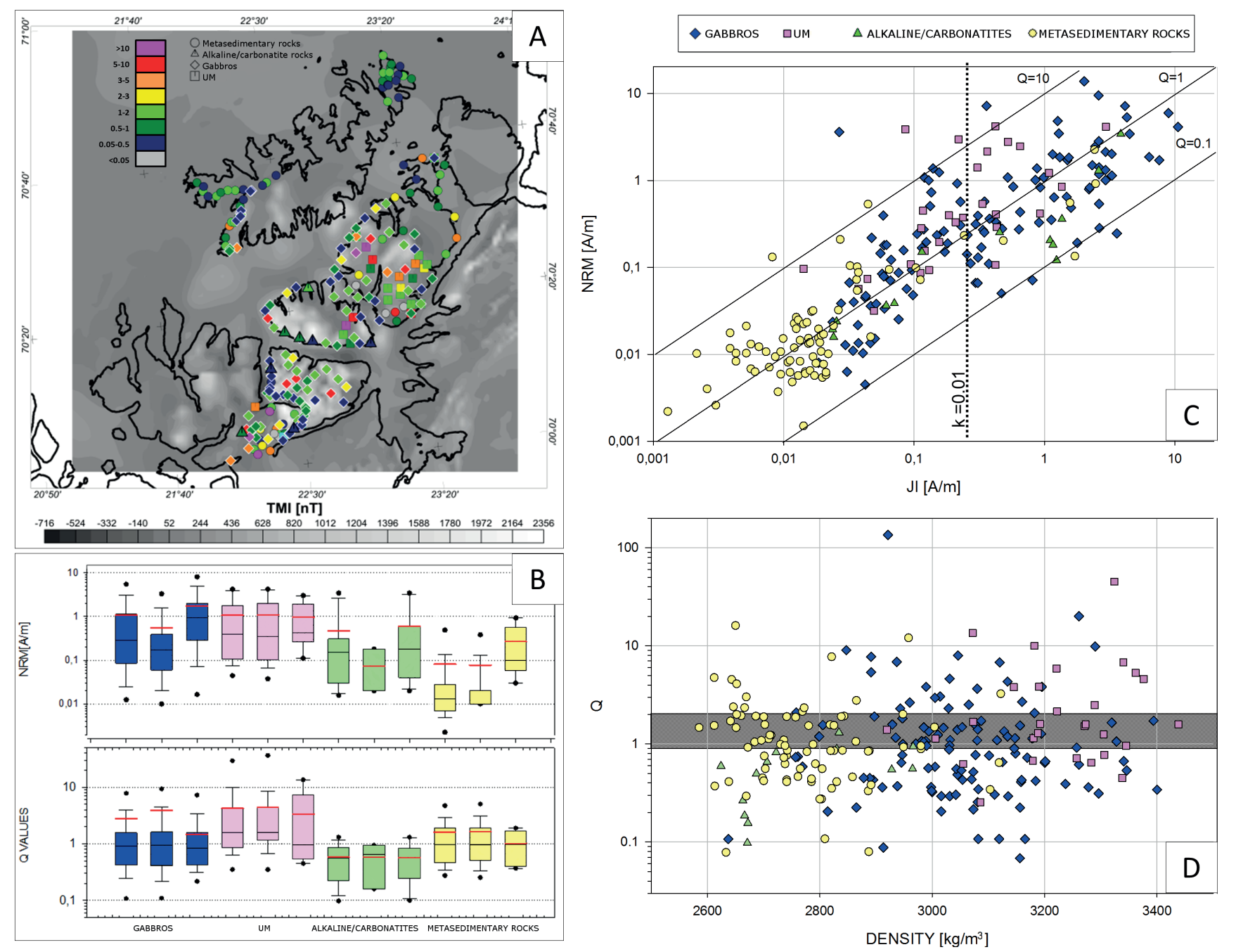

Figure 6. (A) Aeromagnetic anomaly map (grey-scale image) with superimposed Q values. (B) Natural Remanent Magnetisation (NRM) and Q box plots. (C) Q plot: NRM vs. induced magnetisation (Ji). (D) plot of Q vs. density. 


\section{$Q$ values}

Fig. 6A shows the magnetic anomaly map with superimposed $Q$ values (Königsberger Ratio: ratio between natural remanent magnetisation (NRM) and induced magnetisation $\left(\mathrm{J}_{\mathrm{i}}\right)$ ) for the same samples as shown in Fig. 3, apart from the 26 samples which lack remanent magnetisation measurements.

$J_{i}=k($ magnetic susceptibility $) \cdot H($ ambient magnetic field $)$

$\mathrm{Q}=\frac{N R M}{J_{i}}=\frac{N R M}{k \cdot H}$

The $\mathrm{Q}$ values have been calculated considering an ambient magnetic field of $43 \mathrm{~A} / \mathrm{m}(53,700 \mathrm{nT}$, IGRF2010 model). High Q values plot in correspondence with the peridotite bodies and the gabbros in the eastern part of Øksfjord peninsula and on the island of Seiland. The Q plot (Fig. 6C) displays Ji vs. NRM and shows that the rocks have a wide range of NRM values. Approximately $70 \%$ of the samples have $Q$ values above 0.5 and almost half of the samples have Q values above $1.32 \%$ of the samples have Q values plotting between 0.9 and 2 (grey rectangle in Fig. 6D), 20\% have Q values higher than 2 and the remaining $48 \%$ have $\mathrm{Q}$ values below 0.9 (Fig. 6B-D).

Gabbros show a wide distribution in the Q plot: generally, samples with higher NRM $(>1 \mathrm{~A} / \mathrm{m})$ also have relatively high susceptibility $(\mathrm{k}>0.01)$; therefore, the magnetic anomalies will not be dominated by remanence. However, some gabbro samples have lower susceptibilities $(\mathrm{k}<0.01)$ and high NRM. This could be due either to the presence of pyrrhotite, which has a lower susceptibility than magnetite, or finely exsolved members of the hematiteilmenite series that would explain high NRM and low susceptibility values (McEnroe et al., 2001, 2002, 2009a, b, 2016; Robinson et al., 2002). There is no clear correlation between density and $Q$ values in the intrusive rocks of the SIP (Fig. 6D). Within the metasedimentary rocks, samples with lower density have generally higher $\mathrm{Q}$ values, which may be coupled with the decrease in magnetic susceptibility indicating either fewer magnetic oxides or more oxidised rocks, as seen in Fig. 4. Denser UM rocks generally have lower susceptibilities as discussed previously (Fig. 4). Even more complex is the petrophysics of the gabbros that have variable NRM and susceptibility values, which do not correlate with the density.

\section{Method and modelling results}

We applied 3D magnetic modelling (Encom ModelVision $^{\mathrm{TM}}$ ) in order to estimate local sources' geometries and depth extent. The magnetic subsurface is modelled by mean of bodies of constant susceptibility and NRM. The geometry of the body is defined both in cross sections and in the map plane. After creation, bodies can be edited to manipulate their shape and physical properties. Forward modelling is performed by modifying the magnetic properties and/or the geometry of the $3 \mathrm{D}$ bodies in order to minimise the mismatch between the predicted and the observed data.

The magnetic response is calculated by solving an integral for the induced and remanent magnetisation of the bodies (Blakely, 1996). The model presented here has been constructed using frustum bodies, i.e., bodies with horizontal top and bottom bounded by polygons.

The model has been constrained using surface geology and petrophysical data. The bottom of the SIP as derived from gravity modelling (Fig. 2F; Pastore et al., 2016) has also been used as reference for the maximum depth extension of the modelled bodies. The model is built along 10 sections oriented NE-SW and 8 sections with perpendicular strike direction as shown in Fig. 7. Each modelled body has its own susceptibility, selected from the 7 modes of the susceptibility's frequency histograms (Fig. 5; Table 2). The lateral extensions and thicknesses of the bodies were chosen in order to match the wavelength and amplitude of the modelled with observed magnetic anomalies. The background susceptibility of the model is set to 0.0002 SI, based on the metasedimentary rock data. The entire SIP geometric body, derived from the gravity modelling, is assigned a susceptibility value of $0.001 \mathrm{SI}$; within it are the modelled frustum bodies.

Fig. 7 shows the modelled profile locations together with the resulting bodies (model $\mathrm{M} 1$ ) in a $3 \mathrm{D}$ display; the colours of the bodies reflect different susceptibilities. Table 2 summarises the modelling parameters. The names of the bodies in the table are the same as for the bodies shown in Fig. 7. We used a $Q$ value of 1 for all bodies with exception of the peridotites on Seiland; for these we selected a Q value of 6 according to the petrophysical data (see Fig. 6). Due to the lack of measurements of the NRM directions, all the bodies' NRM directions are assumed to be parallel to the present-day Earth's magnetic field. Late mineralisation, due to alteration or metamorphism, could cause the NRM to have the present-day direction. However, little alteration has been reported by previous studies and is commonly found associated with alkaline intrusions as a result of metasomatism and fenitisation of their host rocks (Sturt \& Ramsay, 1965; Roberts et al., 2010) or to ultramafic rocks as result of local serpentinisation (Grant et al., 2016).

According to Robins \& Often (1996) and Roberts et al. (2006), the SIP intrusions were variably deformed during the main Scandian (420 Ma) phase of the Caledonian Orogeny. Although most of the SIP igneous rocks are well preserved (Mørk \& Stabel, 1990), this event significantly affected the SIP. Based on 420-430 Ma 
Table 2. Modelled bodies and corresponding model parameters. The modelling parameters used in model M1 are in grey. Depths values refer to the mean sea level: positive values for below and negative values for above reference line.

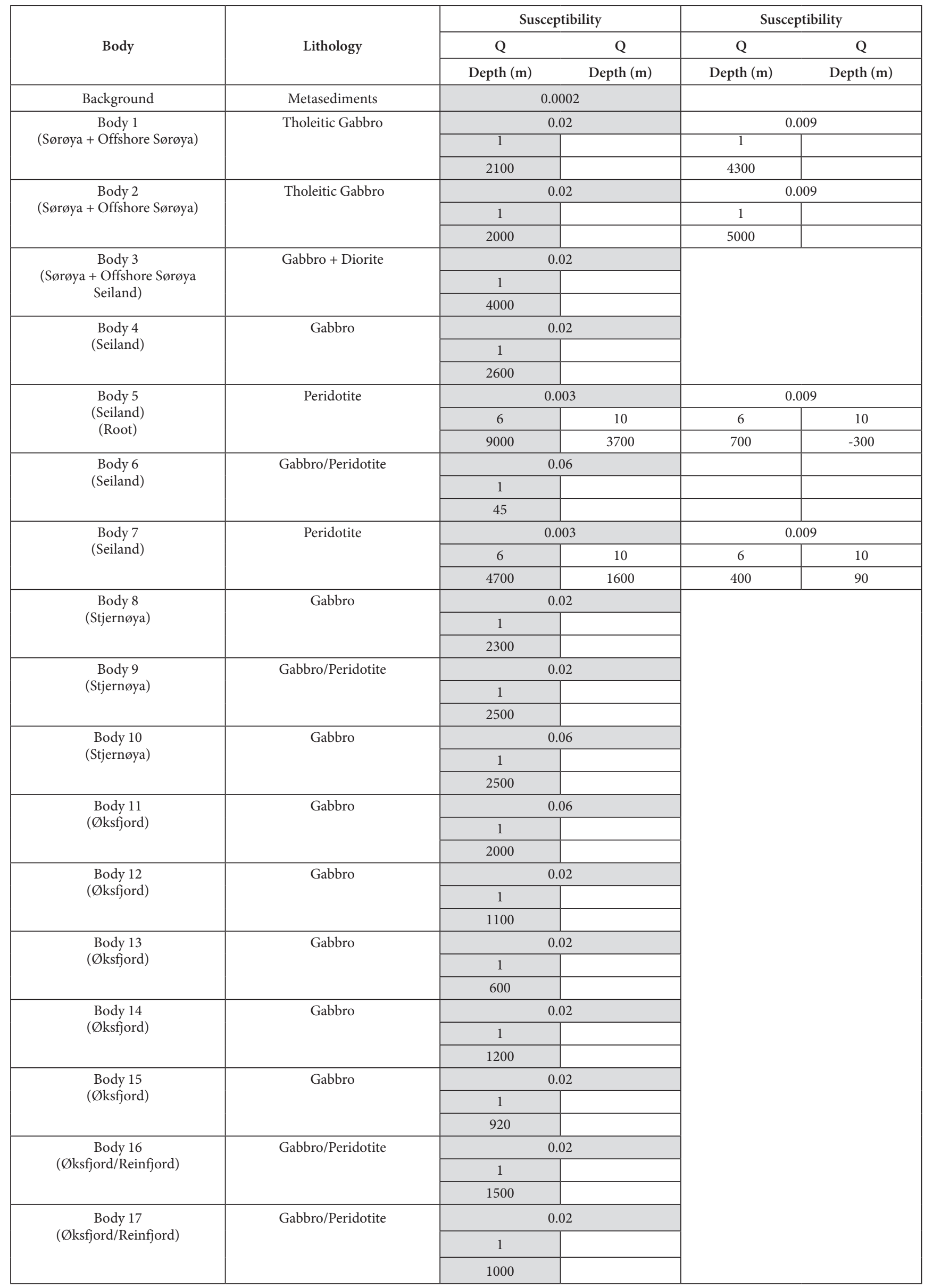



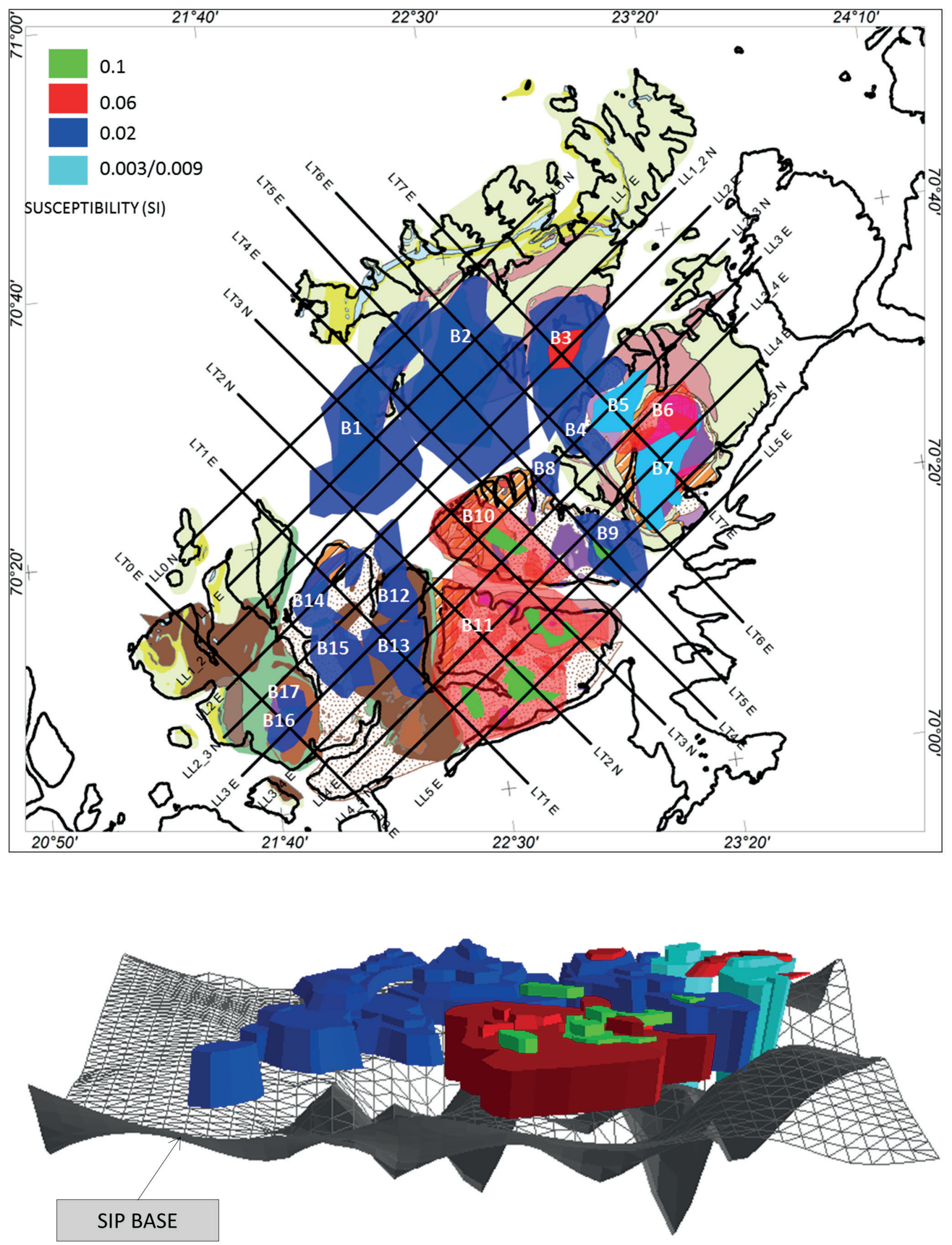

Figure 7. Top: Map display of the modelled bodies superimposed on the geological map; annotation of bodies refers to Table 2. Bottom: $3 D$ view of the modelled bodies with the base of the SIP (grey colour) from gravity modelling (Pastore et al., 2016). 

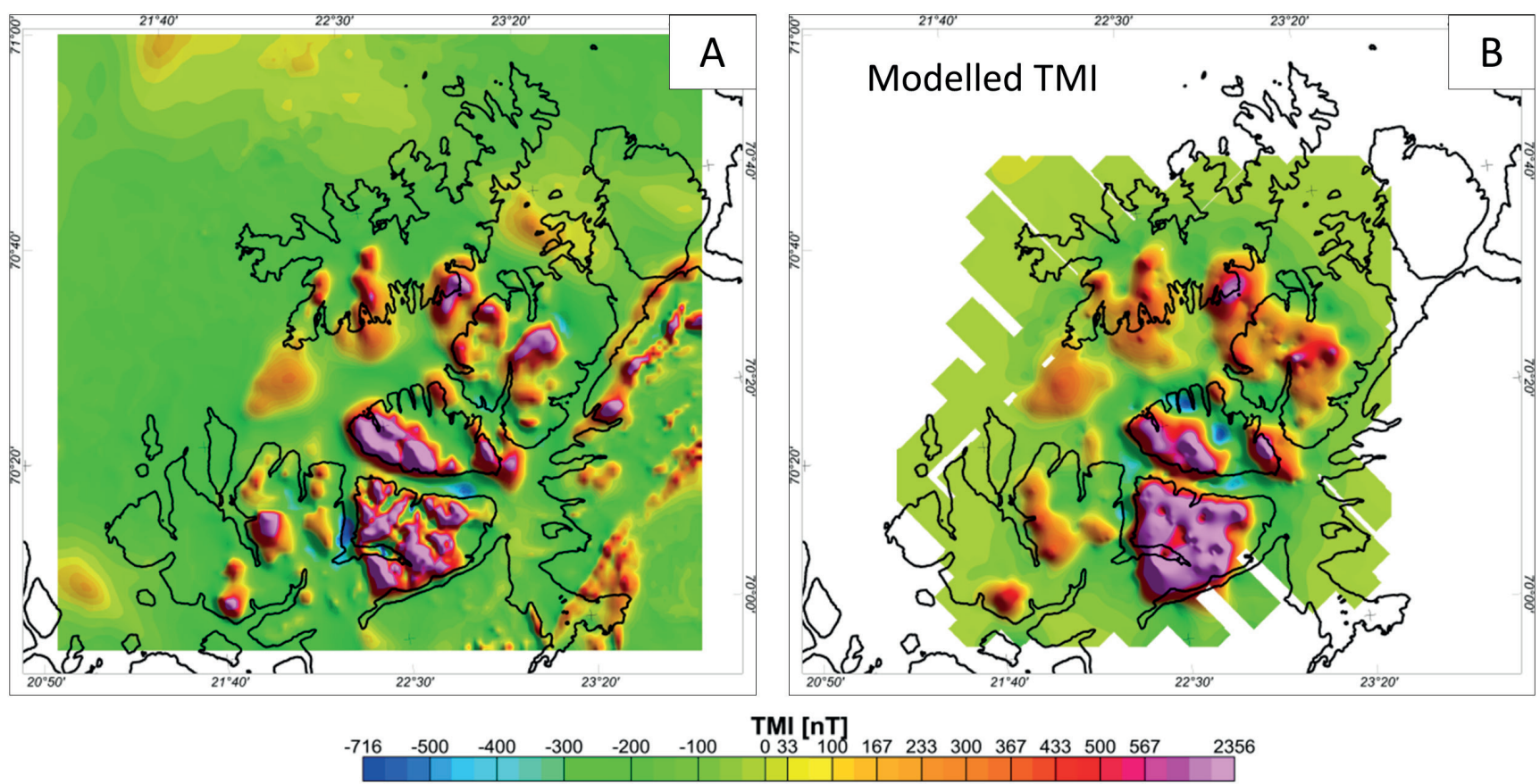

\section{TMI [nT]}

Figure 8. Observed (A) and calculated (B) magnetic anomaly maps.

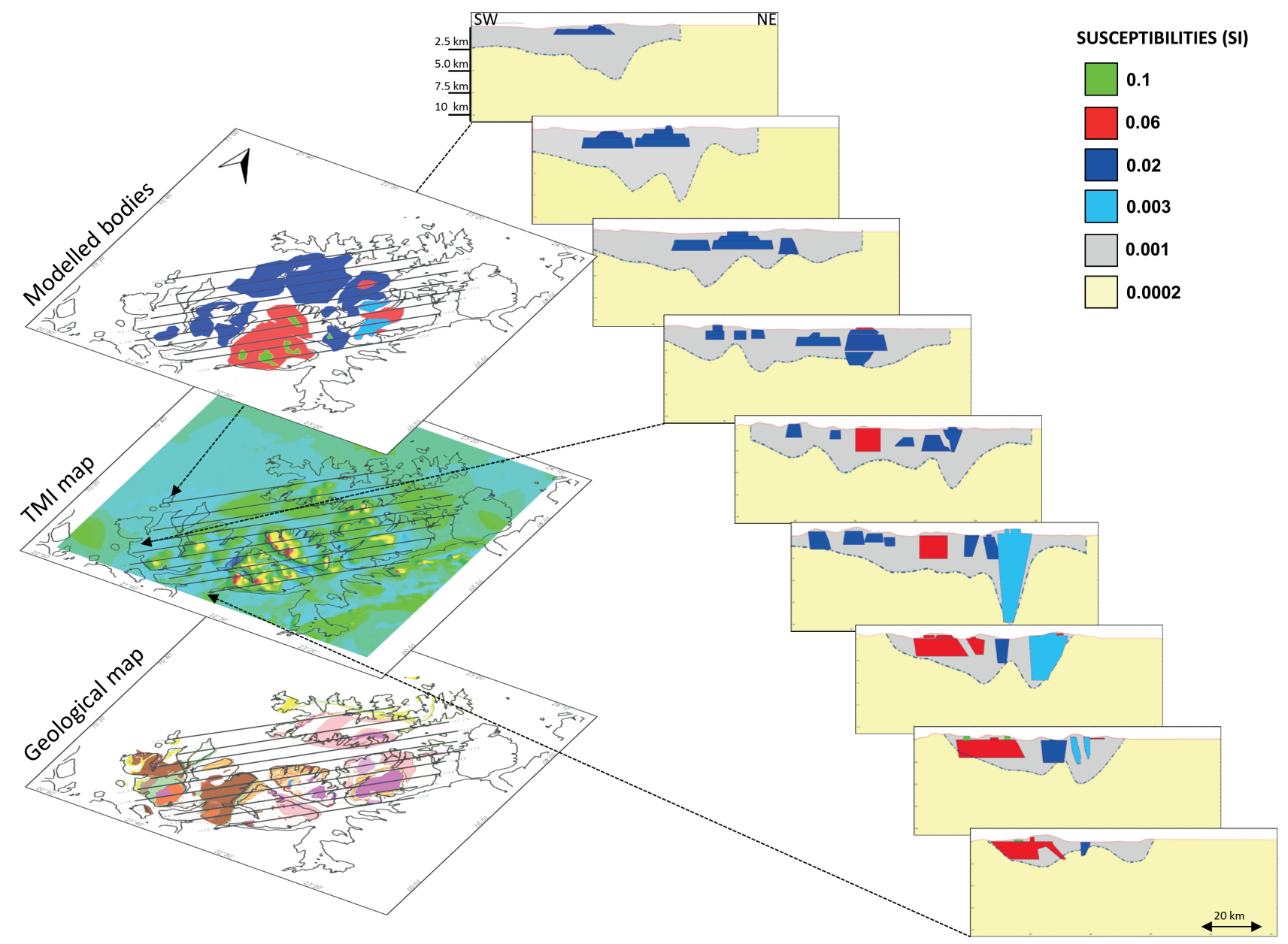

Figure 9. NE-SW oriented modelled sections, map view of the modelled bodies, TMI map and geological map with section profiles. 


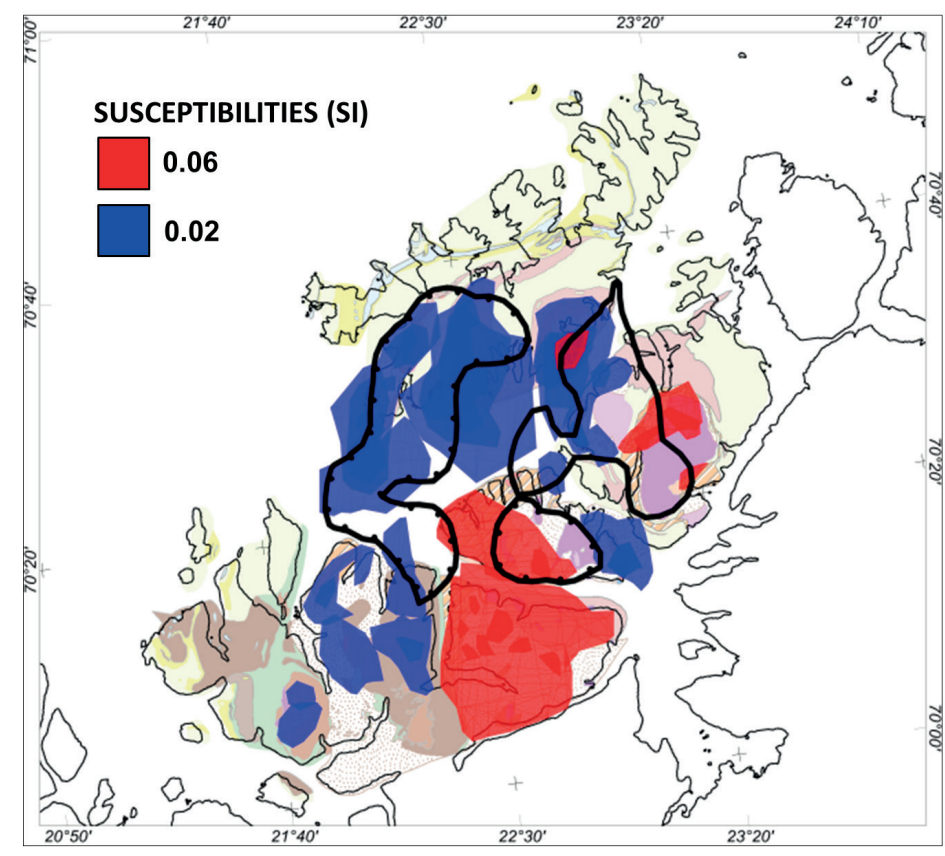

3D VIEW

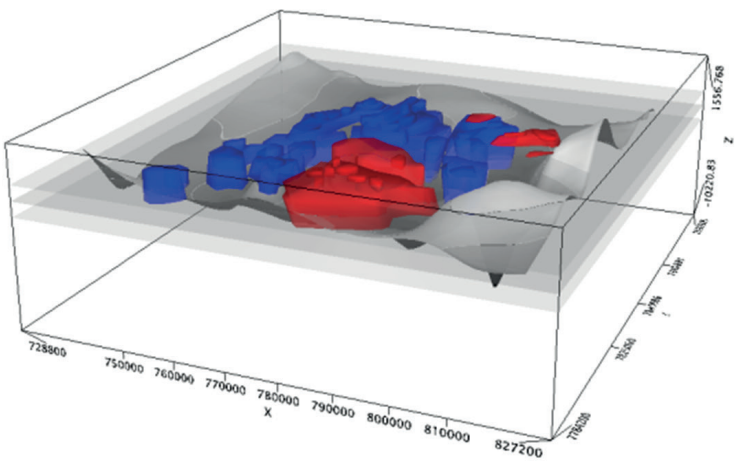

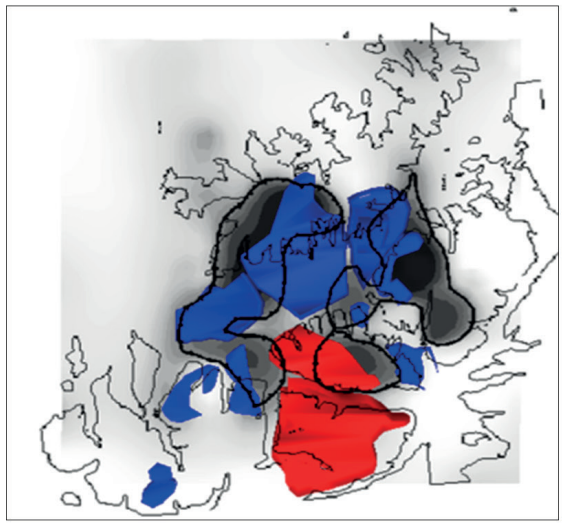

1 km b.s.l.

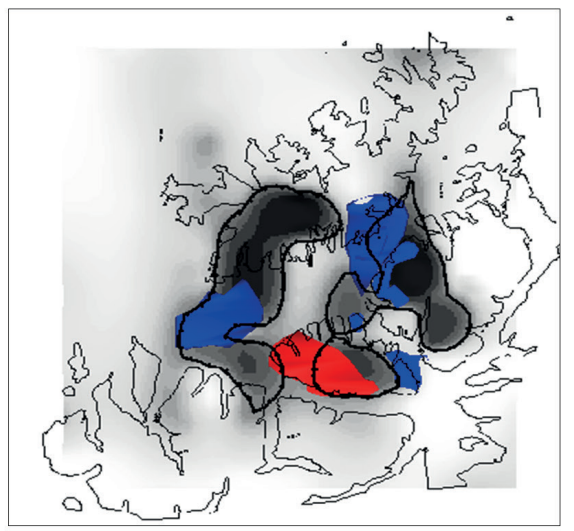

2 km b.s.l.

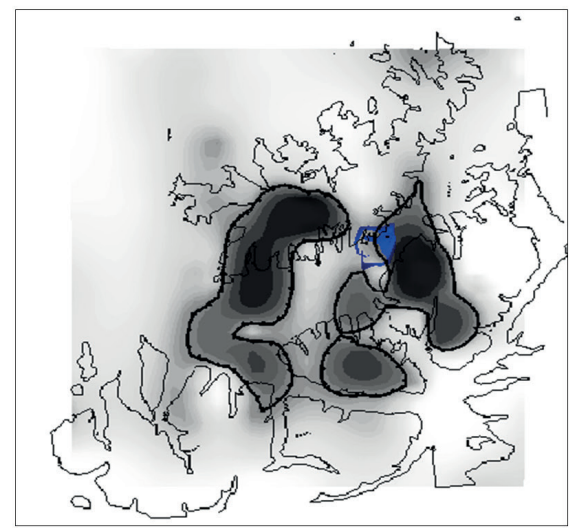

3 km b.s.l.

Figure 10. Depth distribution of the dominant magnetic units (red and blue) assumed to be related to the different gabbro types, in comparison with the gravity-derived roots (black contours): top view of the bodies overlapping the geological map (upper left of the figure), $3 D$ view (upper right of the figure) and three horizontal depth slices of the magnetic bodies (on the bottom of the figure) with outline of the coastline (thin black curves) and of the $4000 \mathrm{~m}$ b.s.l. depth contours (thick black curves) of the base of the SIP (from Pastore et al., 2016).

plate-tectonic reconstructions from Baltica, Scotland and North America (Bullard et al., 1965; Torsvik, 1998), the SIP experienced this metamorphic event when near equatorial latitudes; it is therefore unlikely that metamorphism could explain the NRM directions parallel to the present-day Earth's magnetic field. Based on the above considerations, alternative NRM directions and $\mathrm{Q}$ values were also tested, and the effects on the model are discussed in the next section.

Fig. 8 shows observed and modelled magnetic anomalies for the model M1 shown in Fig. 7. The modelling resulted in a reasonable fit to the anomalies, where the residuals mean value is $23 \mathrm{nT}$ with a standard deviation of $116 \mathrm{nT}$. Model sections striking NE-SW are shown together with the map view of the modelled bodies (model M1), the magnetic anomalies map and the geological map in Fig. 9. Large bodies with susceptibility values of 0.06 SI are located in the southeastern part of the magmatic complex with a maximum depth extent of $2500 \mathrm{~m}$ below sea level (b.s.l.) marked in red on the map. Furthermore, minor bodies with higher susceptibilities (green) are modelled on top of these large magnetic bodies. Bodies with susceptibility of 0.02 dominate the northwestern part of the magmatic complex and locally reach depths of $4000 \mathrm{~m}$. The major ultramafic complexes on the island of Seiland are modelled by two bodies with susceptibilities of $0.003 \mathrm{SI}$; the modelled bodies reach down to the base of the SIP. The depth extent of these bodies would be lower if applying a higher magnetic susceptibility of 0.009 SI (Table 2), which would imply a more complex subsurface geology. 


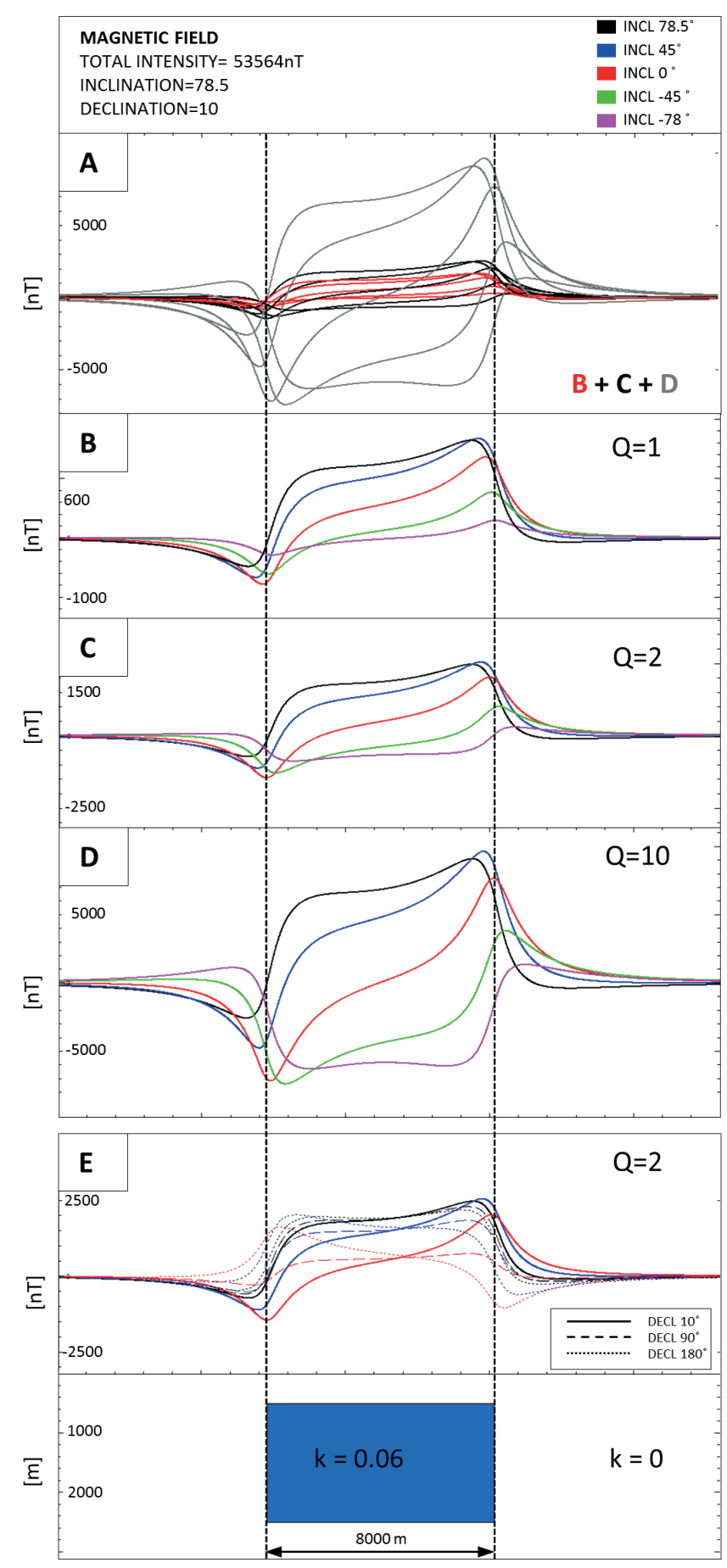

Figure 11. Magnetic anomalies of a circular pipe resulting from changes of NRM inclination and $Q$ values $(B, C, D)$; $(A)$ shows $B, C$ and $D$ together; $(E)$ shows the effect of changing the NRM declination for three NRM inclinations of $0^{\circ}, 45^{\circ}$ and $78^{\circ}$ and a constant $Q$ value of 2 .

Modelled magnetic unit locations were compared with the geometry of the roots derived from gravity modelling in Fig. 10, where the roots are outlined by black contours. For this purpose, horizontal cross sections through the major gabbro bodies modelled by susceptibilities of 0.06 (SI; red) and 0.02 (SI; blue) have been shown. These two susceptibility values represent two different types of gabbro. In the shallower part, the magnetic bodies (in red and blue colours) widen and form large, extensive sheets; they progressively reduce in lateral extent with depth and terminate at a depth of $3 \mathrm{~km}$ b.s.l. The most magnetic gabbro unit (red) terminates at depth in correspondence with the southernmost root below Stjernøya. This location coincides with occurrences of ferroalloys and ferrous metals. This could open for an alternative interpretation of susceptibility higher than $0.06 \mathrm{SI}$, which has been used here. The consequence of this would be a smaller depth extent of the modelled magnetic unit. The less magnetic gabbro units (blue) reach their deepest level in the area between the deepest roots, between Sørøya and Seiland. This observation may link the magnetic attributes of the different gabbroic units to magma migrating from different roots and allows for the possibility of mineralogical differences as addressed in more detail in the discussion chapter.

\section{Sensitivity test for the effect of NRM}

Magnetic anomalies are the cumulative expression of heterogeneities in magnetic susceptibility and natural remanent magnetisation (NRM) in the crust. The expected magnetic anomaly at polar latitudes for a positive contrast in magnetic susceptibility and for a simple shape as, i.e., a sphere or a vertical cylinder, is a positive anomaly centred on the source body and surrounded by a smooth negative anomaly. This behaviour of the magnetic anomalies is a valid assumption for a large part of the SIP because its location is at $70-71^{\circ}$ latitude north, and the induced magnetisation is a significant component of the total magnetisation. However, some rocks of the SIP are locally influenced by high remanence (Fig. 6B, C). Particularly high Q values are observed on the Øksfjord peninsula and Seiland in correspondence with both gabbros and peridotites (Fig. 6). However, we cannot simply apply these $Q$ values in the modelling, because the NGU petrophysical database used here lacks NRM directions. Therefore, the effect of remanence has been investigated on synthetic models and on selected profiles. Fig. 11A shows the effect of changing $\mathrm{Q}$ values on the amplitude of the anomaly for a synthetic model. The model consists of a vertical pipe which has a vertical extent of $2 \mathrm{~km}$, and circular top and bottom surfaces with a diameter of $8 \mathrm{~km}$. The susceptibility of the pipe has been set to 0.06 SI which is representative for the magnetic gabbros exposed on the eastern side of Øksfjord. Models in Fig. 11B-D show the calculated anomaly for $\mathrm{Q}$ values of 1,2 and 10, respectively; all models consider a constant NRM declination of $10^{\circ}$ (same declination as Ji) and different line colours are for different NRM inclinations. The model in Fig. 11E shows the effect of changing the NRM declination for different NRM inclinations with a constant $Q$ value of 2 . The synthetic model illustrates that major changes in amplitude and shape of the 

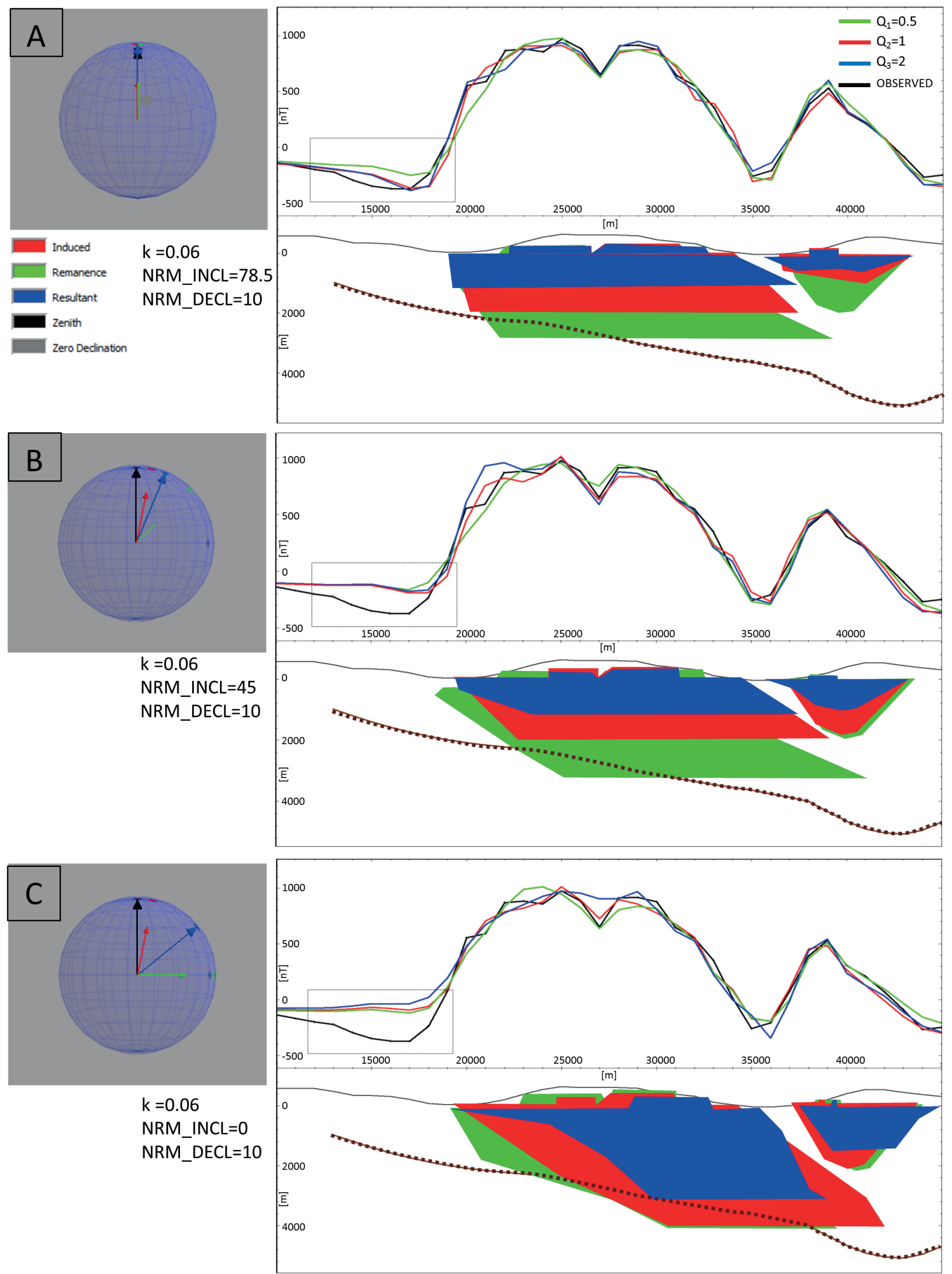

Figure 12. $Q$ value and NRM direction $\left(78.5^{\circ}(A), 45^{\circ}(B)\right.$ and $\left.0^{\circ}(C)\right)$ test on the southeastern part of section LL-4 for the bodies B10 and B11 (see Fig. 6 for location). The modelled bodies are filled by different colours (models in blue $(Q=2)$ overlap models in red $(Q=1)$ and models in green $(Q=0.5)$ ) and the respective calculated anomalies are displayed by the same colours. The base of the SIP derived from gravity modelling (Pastore et al., 2016) is outlined by a brown dotted curve on the depth sections. 
magnetic anomaly occur for high $\mathrm{Q}$ values and shallow NRM inclinations.

Generally, SIP rocks show Q values below $2(\approx 30 \%$ of the SIP samples have Q values between 2 and 0.9 and $48 \%$ of the samples plot below 0.9; Fig. 6). However, locally high $\mathrm{Q}$ values are observed on the Øksfjord peninsula and Seiland and with particularly high NRM values on the eastern side of the Øksfjord peninsula. Therefore we tested the effect that different NRM inclinations would have on the model at this location. The test applied different $Q$ values of $0.5,1$ and 2 ; these were selected according to the petrophysical database (Fig. 6). Fig. 12 shows the variation in depth of the modelled bodies at Øksfjord and Stjernøya (bodies B10 and B11 in Table 2 and Fig. 7) as a consequence of using the different $Q$ values and NRM inclinations $\left(78.5^{\circ}, 45^{\circ}\right.$ and $\left.0^{\circ}\right)$. The test shows that the vertical extent of the bodies is strongly dependent on the Q value used in the model. The geometry of the bodies is further controlled by the NRM inclination. As observed in the synthetic model in Fig. 11, major changes in the amplitude and shape of the magnetic anomaly are expected for high $\mathrm{Q}$ values and shallow NRM inclinations. All models in Fig. 12A-C show a reasonable fit to the observed anomaly (black line) and generally plot above the gravity derived depth of the base of the SIP (brown line). However, the best fit on the left side of the Øksfjord anomaly, indicated by a black dotted box in Fig. 12A-C, is obtained with an NRM inclination of $78.5^{\circ}$ (nearly parallel to the present-day field and hence, Ji; Fig. 12A). The test was made with a fixed declination of $10^{\circ}$. With shallow inclinations, the declination angle can strongly affect the shape of the anomaly, as shown in the synthetic model in Fig. 11. Applying the depth constraint of the SIP from gravity, a matching anomaly was obtained with lower inclinations (Fig. 12B, C). However, such a model would not be able to give a better fit than the one obtained using steeper inclinations. Therefore, we suggest the NRM inclinations on Øksfjord to be of near-polar inclination and, for simplicity, we chose the present-day field inclination in the modelling process. In model M1, shown in Figs. 7, 9 \& 10, the Q value was set to 1 and the NRM direction assumed to be the same as the induced magnetisation direction. Based on the test above, different $Q$ values would give reasonable models within the depth constraint of the base of the SIP, thus leaving uncertainties on the depth extent of the modelled bodies. We are aware that our model is simple, and could be more complex with multiple layers of sources with different magnetisations, but we lack the robust petrophysical data to constrain such a model.

The peridotites on the island of Seiland have high Q values, and were modelled using two $\mathrm{Q}$ values. Results are shown in Fig. 13, and summarised in Table 2. The section shown in Fig. 13 (LT7 in Fig. 7) crosses one of the deep roots of the SIP. On the western side, a body with susceptibility of 0.02 SI is modelled and here interpreted

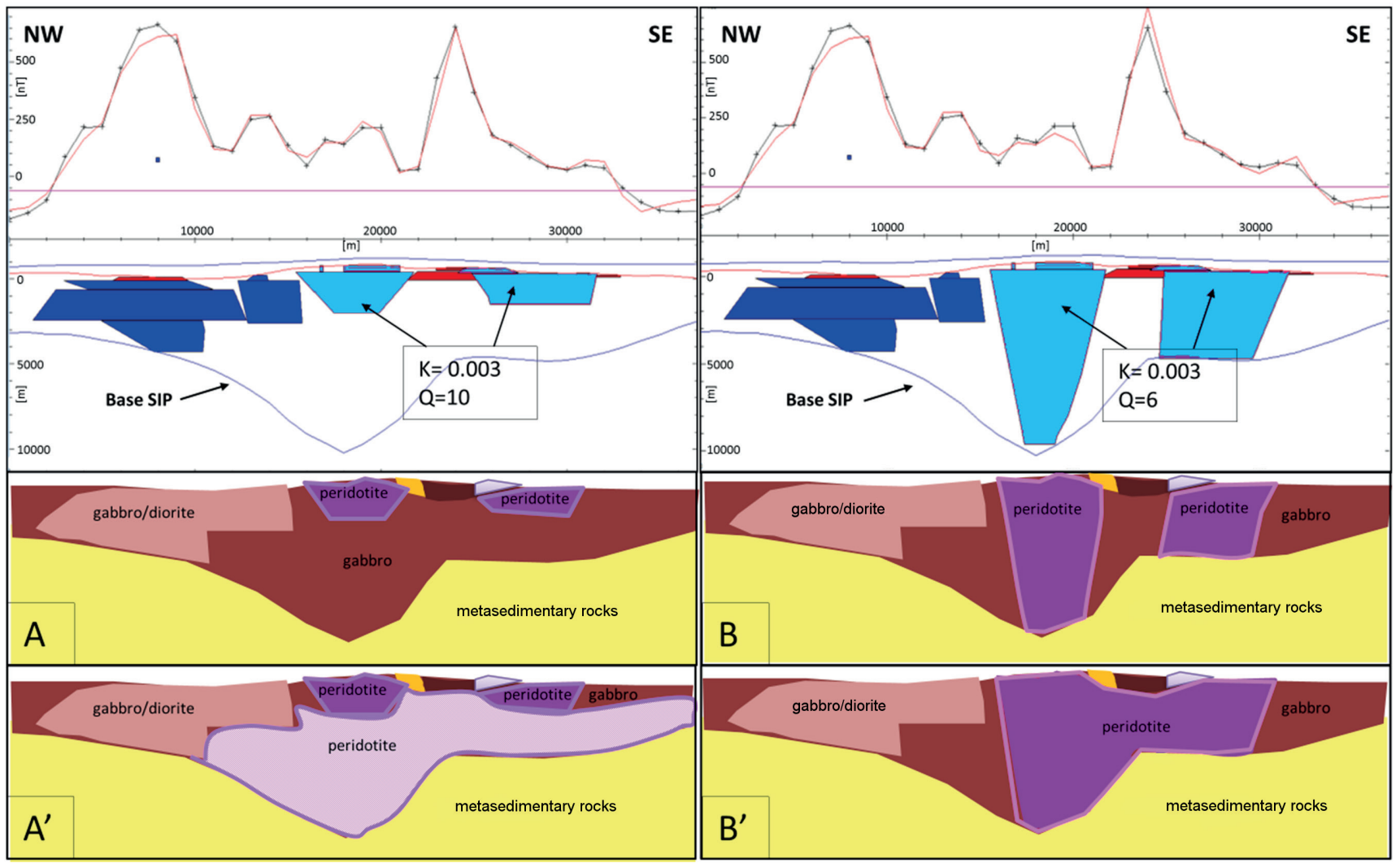

Figure 13. Section 1 (LT7) with magnetic models on top for different $Q$ values and two possible geological interpretations. The observed and modelled curves are shown in black and red, respectively. 


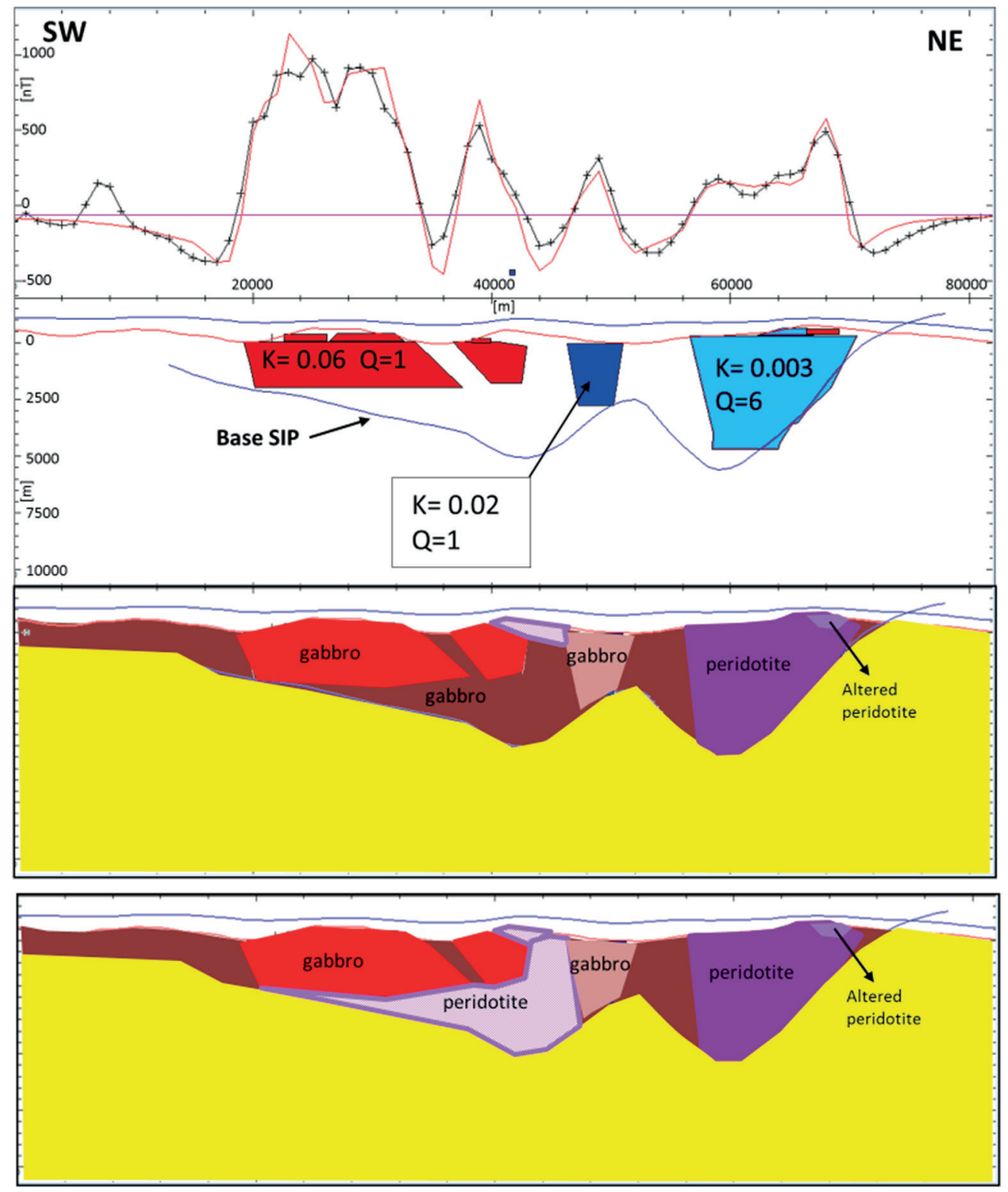

Figure 14. Section 2 (LL4) with magnetic model on top and two possible geological interpretations. The observed and modelled curves are shown in black and red, respectively.

as a magnetic gabbro. The two peridotite bodies that crop out along the section are modelled with a susceptibility of 0.003 SI. In between these peridotites is a body with a higher susceptibility, which has been modelled. Using different $\mathrm{Q}$ values for the peridotite allows for several possible interpretations. The first model (Fig. $13 \mathrm{~A}, \mathrm{~A}$ ) uses a $Q$ value of 10 which results in a depth extent of the peridotite bodies of $4000 \mathrm{~m}$ (peridotite to the west) and $1600 \mathrm{~m}$ (peridotite to the east). The second model (Fig. 13 B, B') uses a $Q$ value of 6, which increases the thicknesses up to the maximum depth, as suggested by gravity modelling (9500 and $4700 \mathrm{~m}$, respectively). If $\mathrm{Q}$ values lower than 6 are used the peridotite bodies must be deeper. However, with the constraining depth of the SIP based on gravity modelling (Pastore et al., 2016), a lower $Q$ value is only possible if the magnetic susceptibility of the peridotite was higher than 0.003 SI. Shown in Fig. 14 is a modelled section crossing the
Øksfjord peninsula to the southwest and Seiland to the northeast (LL4 in Fig. 7). Here, the most magnetic body is located in correspondence with the gabbros at Øksfjord and in the southern part of Stjernøya. Based on the magnetic and gravity (Pastore et al., 2016) modelling results, there is either a non-magnetic gabbro or a peridotite below this magnetic gabbro.

\section{Discussion}

The Seiland Igneous Province, with its unusual deep emplacement setting and petrology represents an outstanding study area with respect to both mineral exploration and deep-crustal magmatic processes. Ferrimagnetic minerals form in different settings and due to different processes (magmatism, weathering 
or metamorphism) and may accumulate in ore deposits. Magnetic anomalies, by reflecting the relative concentration of these minerals, can therefore be used to target potential areas for economic minerals. Below, we discuss the magnetic modelling results with respect to the petrology, and to the prospective potential of the province. Furthermore, the magnetic modelling results are also discussed with respect to the geometrical configuration of the province, which includes multiple roots and likely magmatic feeder zones. These are regarded as critical areas, and provide potential conditions for ore mineralisation with possible metamorphic reactions between the host rock and the intrusions, for focused fluid flow and late alteration zones.

\section{Magmatic petrology and magnetic anomalies in the SIP}

Modelling of the magnetic anomalies suggests a different magnetic character in the southeastern part of the magmatic province with respect to the northern part as shown in Figs. 7, $9 \& 10$. This was also recognised in the distribution of the densities and magnetic attributes shown in Fig. 3, where areas A and B were shown to carry different characteristic values that can be explained by a high content of ferromagnetic iron oxides or sulphide minerals as discussed above. This behaviour can be due to differences in petrology and also could be related to magma differentiation, metamorphism and/or alteration. According to Robins \& Gardner (1974), three different gabbros are found in the SIP, and some of these gabbros are strongly deformed whereas others preserve their original layering and show a cumulate texture. Gabbroic rocks in the Seiland Province vary in composition from tholeiitic to alkaline. The three main types of gabbro as identified by Robins \& Gardner (1974) are tholeiitic gabbro, syenogabbro and alkaline gabbro. According to Robins \& Often (1996), the oldest gabbros in the SIP are the Storelv and the Breivikbotn intrusions on Sørøya. The large gabbroic intrusions on Seiland, Stjernøya and the Øksfjord peninsula document instead a later magmatic activity which involved magmas of more alkaline affinity (Robins \& Takla, 1979; Pedersen et al., 1989). There is no clear correlation between the distribution of these gabbro types and the magnetic classification, which indicates a higher complexity in the petrology. Composition, metamorphism or alteration could result in a variation in the direction and intensity of the NRM of the rocks by modifying concentrations or grain sizes of ferrimagnetic minerals and even mask the magnetism of the rocks. However, most of the samples from areas of low-magnetic anomalies, i.e., in the northern part of Stjernøya, have relatively low magnetic susceptibilities $(<0.01)$ and $\mathrm{Q}$ values below 1, therefore excluding these anomalies as having been caused by different NRMs because the contribution of the NRM to the total magnetisation is very low.
To investigate further the geology in these areas we include the new radiometric data (Geological Survey of Norway; Nasuti et al., 2015) over Stjernøya and eastern Oksfjord (Fig. 15). Radiometric data can aid in defining boundaries between rock types and are commonly used to locate areas of alteration and/or changes in mineralogy (Dentith \& Mudge, 2014). Generally, mafic and ultramafic rocks have little natural radioactivity. Most of the gamma-radiations measured in radiometric surveys generally have their source in the uppermost $30-50 \mathrm{~cm}$ of the crust (Nasuti et al., 2015) and therefore topography and Quaternary deposits may control the distribution of the radioactive isotopes. Although we observed a lack of correlation between the radioactive isotope concentrations and the distribution of Quaternary deposits (http:/geo.ngu.no/ kart/losmasse_mobil/), the magnetic sources, modelled with a depth extent between 2 and $3 \mathrm{~km}$ at these locations, do not necessarily reflect the first few centimetres of crust. We do observe a general enrichment in potassium within the modelled magnetic unit area (outlined by a dashed red line in Fig. 15) but strong concentrations only correlate well with the alkaline rocks on Stjernøya, and with the syenitic rocks on Øksfjord. The latter, as suggested by the radiometric data, likely continue, as a narrow band, across the layered gabbro. Furthermore, we observe high concentrations in potassium (K) and thorium (Th) along the western side of the Øksfjord peninsula in Fig. 15, corresponding to the foliated syenogabbro, and to the south of the gneissic rocks. This also marks the boundary of the modelled magnetic unit. This relatively enriched area of potassium in the southern part of Stjernøya and eastern Oksfjord, compared to the northern part of Stjernøya, suggests that these gabbros have different petrological compositions. These highly radiogenic areas are also highly magnetic. The relatively low concentration of radioactive elements on the northern side of Stjernøya, may also reflect the abundance of ultramafic rocks, as these cover large parts of that area. It is possible that the gabbros on that side of the island were affected by the emplacement of the ultramafic rocks.

From geological mapping it is known that most of the SIP intrusions show a layered structure and variable compositions which may result in varying magnetic properties, and if the magnetite content varies then the magnetic susceptibility of the gabbros will be different. This variability likely reflects the variable effect of the crystal fractionation in the multiple magmatic pulses, which fed the SIP intrusions (Robins \& Often, 1996; Roberts, 2007). Particularly temperature and oxygen fugacity can strongly control the fractionation of minerals, and especially ferrimagnetic minerals. These variations are well documented in the magnetic anomalies in the Bjerkreim-Sokndal (BKS) layered intrusion in southern Norway (McEnroe et al, 2001, 2004, 2009a; Robinson et al. 2001).

Layered mafic complexes are commonly known for hosting titaniferous magnetite and ilmenite deposits 

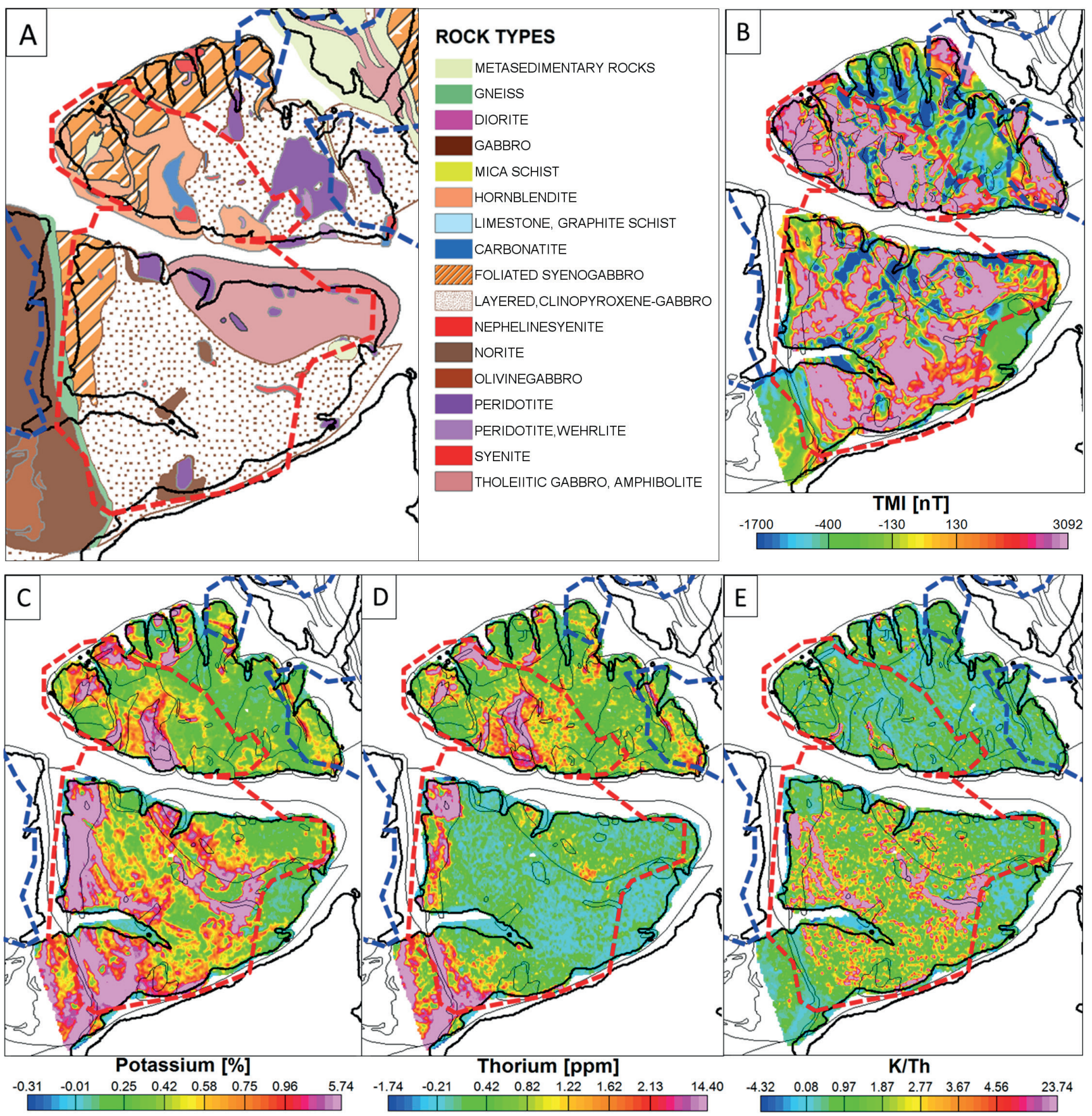

Figure 15. Stjernøya and the eastern side of the Øksfjord peninsula with outline of the modelled magnetic units (red and blue dashed lines) overlaying the geological map (A), the magnetic anomalies map (B), the potassium $(K)$ concentrations map $(C)$, the thorium (Th) concentrations map (D) and the K[\%]/Th[ppm] map (E).

(Korneliussen et al., 1985). The mafic rocks of the SIP are no exception; occurrences of Fe-Ti oxides have been described by Robins (1985) and found associated with both mafic and alkaline complexes.

According to Morse (1980), the fractionation stage at which a basaltic magma becomes saturated in $\mathrm{Fe}-$ Ti oxides depends mainly on its initial composition with respect to oxygen content and silica activity. The SIP intrusions originated in multiple pulses, therefore different temperatures are also possible, from melts with different compositions and different silica activity which influences the fractionation of titanium between silicate and oxide phases (Robins, 1985). These parameters could strongly affect the magnetic properties of the rocks and thus the distribution of the magnetic anomalies. Based on the magnetic modelling results, we suggest the gabbros from the southeastern part of the magmatic complex to be more enriched in ferromagnetic minerals; however, more petrological studies are needed to characterise the magnetic carriers and the factors controlling their petrology and composition. 
The different magnetic character of the modelled gabbros here is most likely related to the magma differentiation. Support for this interpretation includes, (1) the large size of the magnetic bodies as contact metamorphism or alteration generally act on a more local scale, (2) the petrological knowledge as discussed above, (3) geometric distribution with respect to the roots (Fig. 10) and (4) the location of ore mineralisation discussed below.

\section{Magnetic anomalies and deep roots}

Here, we have shown that sources of the magnetic anomalies are located near the contacts of the ultramafic intrusions, on the top of the deep roots, and are related to the gabbro bodies. The deep roots are interpreted to be composed of weakly magnetic rocks as illustrated in Fig. 13. As shown in Fig. 10, the modelled magnetic units gradually taper downwards and at a depth of $2 \mathrm{~km}$ below sea level these units become more focused around the deep roots. The depth of these magnetic units, with a maximum of $3 \mathrm{~km}$, is much shallower than the deeperreaching gravity-derived roots, which extend down to at least $9 \mathrm{~km}$ depth (Pastore et al., 2016). This basal depth of the SIP is well within the gravity uncertainties which relate to the densities applied to the SIP body, where a range of models is possible within the density range of 3100 and $3300 \mathrm{~kg} / \mathrm{m}^{3}$ (Pastore et al., 2016, fig. 9).

In areas where the magnetic units are interpreted as gabbros, the density model might be changed to a lower density because the average density of the gabbros is lower than that of the ultramafic rocks (Table 1). In order to match the gravity anomalies with a body of minor density, the thickness of the body needs to be increased. This results in an increased thickness for the SIP at these locations. A model integrating the magnetic and the gravity data will therefore result in an increased depth for the base of the SIP where the magnetic units are thicker, and will also cause a minor increase in the depth of the modelled deep roots.

Locations with relatively high $\mathrm{Q}$ values of the modelled peridotites were identified at the eastern side of the Øksfjord peninsula and on Seiland. These values indicate that the rocks at these locations may contain an increased amount of pyrrhotite and/or iron oxides.

It is likely that both tectonic and alteration processes have affected the magnetic properties of the rocks. As discussed in the petrophysical data section, serpentinisation could explain the increase in the magnetic susceptibilities and decrease of densities of the peridotites observed at the northern side of the Nordre Bumannsfjord ultramafic complex, on Seiland. The process of serpentinisation can occur in different settings, and it can be observed on different scales; at shallow depth, it commonly occurs along preferential pathways for fluids such as faults or fractures. This process produces magnetite by oxidation of the iron component present in olivine and pyroxenes of the ultramafic rocks and can strongly affect the magnetic properties of the rock; an overview on the serpentinisation settings and reactions is given in Evans et al. (2013). On Seiland and particularly at the location mentioned above, where the peridotites locally show low densities and high magnetic susceptibility, the serpentinisation acts on a small scale, leading to short wavelengths of the magnetic signal. The largest magnetic source in the SIP is located at the southeastern side of the magmatic complex in eastern Øksfjord and on Stjernøya and far from the deep ultramafic roots of the complex which, according to the gravity modelling by Pastore et al. (2016), are located north of the Øksfjord peninsula. Furthermore, ultramafic rocks are also found in the southern part of the magmatic complex and therefore far from the deep ultramafic roots. Examples are the Reinfjord and the Tappeluft ultramafic complexes on the Øksfjord peninsula.

\section{Metal and mineral deposits}

We have inspected the NGU (Geological Survey of Norway) mineral resources database for ferrous metal deposits within the SIP. Most of these deposits are located in areas of high positive magnetic anomalies (Fig. 16B) and are found near or adjacent to the UM complexes, or within the gabbroic rocks (Fig. 16C). It is noted, particularly on the island of Stjernøya, that most of the metal deposits plot around one of the roots of the SIP (Fig. 16A); in association with an alkaline complex within hornblende clinopyroxenites to the southwest, and to the south and northeast of the ultramafic complex of Kvalfjord.

Fig. 16D shows the depth slice at $2 \mathrm{~km}$ of the dominant magnetic units (red and blue, see Fig. 10) in comparison with the gravity-derived roots (thick black curves) and the occurrence of the ferroalloys and ferrous metals. The magnetic unit shown in the red colour correlates with an accumulation of metal deposits. A high amount of ferroalloys and ferrous metals is expected to give high magnetic susceptibilities and most likely a strong induced magnetic anomaly.

\section{Conclusions}

The Seiland Igneous Province has a minimum volume of mafic and ultramafic rocks of $17,000 \mathrm{~km}^{3}$ (Pastore et al., 2016) and is a potential tank for economically valuable deposits. Furthermore, the setting for the deep emplacement of these rocks and the magmatic history of the province are interesting for assessing factors which control the emplacement of magmas in large igneous provinces, such as the SIP. 

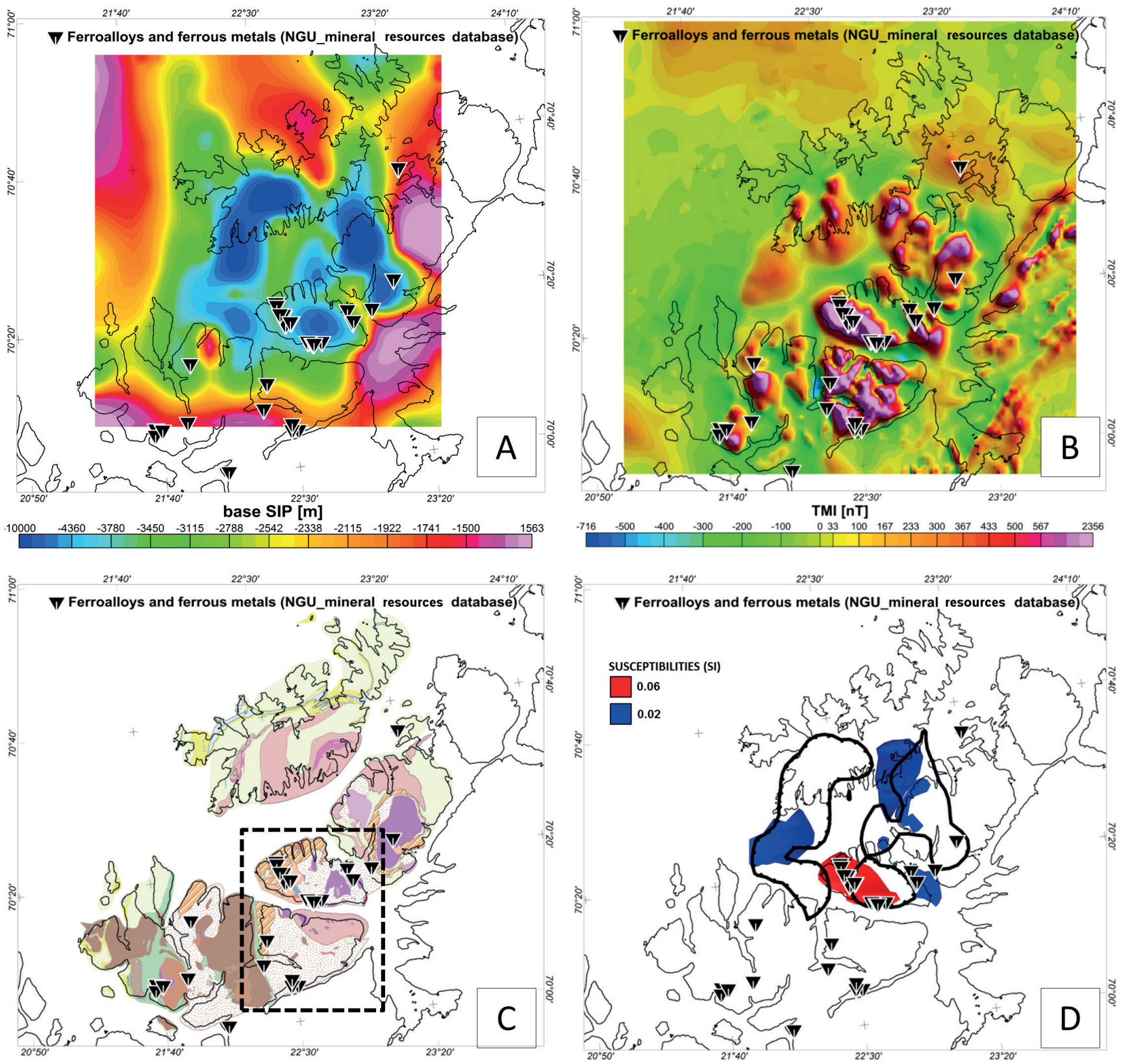

Figure 16. Ferroalloy and ferrous metal occurrences in the SIP (NGU mineral resources database) superimposed on maps of the base of the SIP (A), magnetic anomaly map (B), geological map (C) and on the $2 \mathrm{~km}$ depth slice of the modelled gabbros (D) (see Fig. 10). The black dashed box outlines the area shown in Fig. 15.

Here, we focused on the magnetic signature of the SIP, which reflects compositional heterogeneities. Modelling of the magnetic anomalies aided in mapping these heterogeneities with respect to the known geology of the province. The main results and conclusions are summarised below:

- Magnetic modelling defines better the extent of the SIP in the offshore areas where no samples were available. The magnetic modelling results confirm that the SIP continues offshore as previously suggested by the gravity model of the SIP (Pastore et al., 2016).

- The modelled magnetic units gradually taper downwards, and at a depth of $2 \mathrm{~km}$ below sea level these units become more focused, and are located mostly around some of the deep roots. The depth of these magnetic units reaches a maximum of $3 \mathrm{~km}$, shallower than the gravity-derived roots. This implies that most of the deeper part of the SIP is only weakly magnetic, and that the gravity anomaly is primarily due to a paramagnetic, or weakly magnetic, and dense ultramafic body.

- Magnetic modelling further indicates that the sources of the magnetic anomalies are located around the ultramafic intrusions, and in association with the gabbros. However, the largest magnetic anomaly is 
located in the southeastern part of the magmatic complex, at the eastern side of the Øksfjord peninsula, and far from the deep ultramafic roots of the SIP defined by the gravity modelling. These gabbros have a strong magnetic signature, and are most likely different from the gabbros found in the northern parts of the province.

- As indicated by the $\mathrm{Q}$ values in the petrophysical database, large parts of the SIP have low remanent magnetisation, but local areas with high NRMs are present and have been investigated. Due to the lack of data on NRM directions, sensitivity tests were made. These results suggest that the rocks at the magnetic anomaly at Øksfjord probably have a steep NRM inclination. In order to improve the interpretation of the magnetic anomalies, more data on NRM directions are required.

- Several metal deposits are located throughout the SIP and these are found to be associated with the ultramafic complexes. On Stjernøya, these deposits are located around one of the roots of the SIP which we suggest could have acted as a preferential pathway for the fluids at this location.

Acknowledgements. We thank Alexander Michels and Rune B. Larsen for constructive comments, the reviewers Aziz Nasuti and Carmen Gaina and the editor Trond Slagstad. The research leading to these results was funded by People Programme (Marie Curie Actions) of the European Union's Seventh Framework Programme FP7/2007-2013/under REA - Grant Agreement n608001 'ABYSS' and NFR grant 222666 to S.A. McEnroe.

\section{References}

Blakely, R.J. 1996: Potential theory in gravity and magnetic applications. Cambridge University Press, $441 \mathrm{pp}$.

Brooks, M. 1970: A gravity survey of coastal areas of West Finnmark, Northern Norway. Quarterly Journal of the Geological Society, London, 125, 171-192

Bullard, E., Everett, J. \& Smith, A.G. 1965: The fit of the continents around the Atlantic. Philosophical Transactions of the Royal Society A 258, 41-51. https://doi.org/10.1098/rsta.1965.0020.

Clark, D.A. 1997: Magnetic petrophysics and magnetic petrology: aids to geological interpretation of magnetic surveys. AGSO Journal of Australian Geology and Geophysics 17, 83-104.

Daly, R.A., Manger, G.E. \& Clark, J.S.P. 1966: Section 4: Density of rocks. In Clark, J.S.P. (ed.): Handbook of Physical Constants Geological Society of America, pp. 19-26.

Dentith, M. \& Mudge, S.T. 2014: Geophysics for the mineral exploration geoscientist. Cambridge University Press, 438 pp.

EON Geoscience Inc. 2015: Troms-Finnmark fixed wing aeromagnetic survey 2014 (TROFI-14). Report EON Geosciences Inc., Montréal, Quebec, Canada, 34 pp.

Ernst, R.E. 2007: Mafic-ultramafic large igneous provinces (LIPs): Importance of the pre-Mesozoic record. Episodes 30, 108-114.

Evans, B., Hattori, K. \& Baronnet, A. 2013: Serpentinite: what, why, where? Elements 9, 99-106.

https://doi.org/10.2113/gselements.9.2.99.
(IGRF) International Association of Geomagnetism and Aeronomy 2010: International Geomagnetic Reference Field - 11th Generation. National Geophysical Data Center, NOAA. https://doi.org/10.7289/V58050JN [November 2016].

Grant, T.B., Larsen, R.B., Anker-Rasch, L., Grannes, K.R., Iljina, M., McEnroe, S., Nikolaisen, E., Schanche, M. \& Øen, E. 2016: Anatomy of a deep crustal volcanic conduit system; the Reinfjord ultramafic complex, Seiland Igneous Province, northern Norway. Lithos 252, 200-215. https://doi.org/10.1016/j.lithos.2016.02.020.

Korneliussen, A., Geis, H.P., Gierth, E., Krause, H., Robins, B. \& Schott, W. 1985: Titanium ores: an introduction to a review of titaniferous magnetite, ilmenite and rutile deposits in Norway. Norges geologiske undersøkelse Bulletin 402, 7-23.

Larsen, R.B., Grant, T., Sørensen, B.E., Tegner, C., McEnroe, S., Pastore, Z., Fichler, C., Nikolaisen, E., Grannes, K.R. \& Church, N. 2018: Portrait of a giant deep-seated magmatic conduit system: The Seiland Igneous Province. Lithos 296, 600-622. https://doi.org/10.1016/j.lithos.2017.11.013.

McEnroe, S.A., Robinson, P. \& Panish, P.T. 2001: Aeromagnetic anomalies, magnetic petrology, and rock magnetism of hemoilmenite-and magnetite-rich cumulate rocks from the Sokndal Region, South Rogaland, Norway. American Mineralogist 86, 14471468. https://doi.org/10.2138/am-2001-11-1213.

McEnroe, S., Harrison, R., Robinson, P. \& Langenhorst, F. 2002: Nanoscale haematite-ilmenite lamellae in massive ilmenite rock: an example of 'lamellar magnetism' with implications for planetary magnetic anomalies. Geophysical Journal International 151, 890912. https://doi.org/10.1046/j.1365-246X.2002.01813.x.

McEnroe, S., Brown, L. \& Robinson, P. 2004: Earth analog for Martian magnetic anomalies: Remanence properties of hemo-ilmenite norites in the Bjerkreim-Sokndal Intrusion, Rogaland, Norway. Journal of Applied Geophysics 56, 195-212. https://doi.org/10.1016/S0926-9851(04)00052-7.

McEnroe, S.A., Brown, L.L. \& Robinson, P. 2009a: Remanent and induced magnetic anomalies over a layered intrusion: Effects from crystal fractionation and magma recharge. Tectonophysics 478, 119134. https://doi.org/10.1016/j.tecto.2008.11.021.

McEnroe, S.A., Fabian, K., Robinson, P., Gaina, C. \& Brown, L.L. 2009b: Crustal magnetism, lamellar magnetism and rocks that remember. Elements 5, 241-246. https://doi.org/10.2113/gselements.5.4.241.

McEnroe, S.A., Robinson, P., Miyajima, N., Fabian, K., Dyar, D. \& Sklute, E. 2016: Lamellar magnetism and exchange bias in billionyear-old titanohematite with nanoscale ilmenite exsolution lamellae: I. Mineral and magnetic characterization. Geophysical Journal International 206, 470-486. https://doi.org/10.1093/gji/ggw155.

Morse, S. 1980: Kiglapait mineralogy II: Fe-Ti oxide minerals and the activities of oxygen and silica. Journal of Petrology 21, 685-719. https://doi.org/10.1093/petrology/21.4.685.

Mørk, M. \& Stabel, A. 1990: Cambrian Sm-Nd dates for an ultramafic intrusion and for high-grade metamorphism on the Øksfjord peninsula, Finnmark, North Norway. Norsk Geologisk Tidsskrift 70, 275-291.

Nasuti, A., Roberts, D., Dumais, M.A., Ofstad, F., Hyvönen, E., Stampolidis, A. \& Rodionov, A. 2015: New high-resolution aeromagnetic and radiometric surveys in Finnmark and North Troms: linking anomaly patterns to bedrock geology and structure. Norwegian Journal of Geology 95, 217-243.

Olesen, O., Brönner, M., Ebbing, J., Gellein, J., Gernigon, L., Koziel, J., Lauritsen, T., Myklebust, R., Pascal, C. \& Sand, M. 2010: New aeromagnetic and gravity compilations from Norway and adjacent areas: methods and applications. Geological Society of London, Petroleum Geology Conference series 7, Geological Society of London, pp. 559-586. https://doi.org/10.1144/0070559. 
Pastore, Z., Fichler, C. \& McEnroe, S.A. 2016: The deep crustal structure of the mafic-ultramafic Seiland Igneous Province of Norway from 3-D gravity modelling and geological implications. Geophysical Journal International 207, 1653-1666. https://doi.org/10.1093/gji/ggw362.

Pedersen, R.B., Dunning, G. \& Robins, B. 1989: U-Pb ages of nepheline syenite pegmatites from the Seiland Magmatic Province, N Norway. In Gayer, R.A. (ed.): The Caledonide Geology of Scandinavia, Springer, pp. 3-8. https://doi.org/10.1007/978-94-009-2549-6_1.

Roberts, R.J. 2007: The Seiland Igneous Province, northern Norway: age, provenance, and tectonic significance, $\mathrm{PhD}$ thesis, University of Witwatersrand, 241 pp.Roberts, R.J., Corfu, F., Torsvik, T., Ashwal, L. \& Ramsay, D.M. 2006: Short-lived mafic magmatism at 560-570 $\mathrm{Ma}$ in the northern Norwegian Caledonides: $\mathrm{U}-\mathrm{Pb}$ zircon ages from the Seiland Igneous Province. Geological Magazine 143, 887903. https://doi.org/10.1017/S0016756806002512.

Roberts, R.J., Corfu, F., Torsvik, T., Hetherington, C. \& Ashwal, L. 2010: Age of alkaline rocks in the Seiland igneous province, northern Norway. Journal of the Geological Society 167, 71-81. https://doi.org/10.1144/0016-76492009-014.

Robins, B. 1985: Disseminated Fe-Ti oxides in the Seiland magmatic province of Northern Norway. Norges geologiske undersøkelse Bulletin 402, 79-91.

Robins, B. \& Often, M. 1996: The Seiland Igneous Province, North Norway. Field Trip Guidebook, IGCP project 336, NGU Report 96.127, 34 pp.

Robins, B. \& Gardner, P. 1974: Synorogenic layered basic intrusions in the Seiland petrographic province, Finnmark. Norges geologiske undersøkelse Bulletin 312, 91-130.

Robins, B. \& Takla, M.A. 1979: Geology and geochemistry of a metamorphosed picrite-ankaramite dyke suite from the Seiland Province, northern Norway. Norsk Geologisk Tidsskrift 59, 67-95.

Robinson, P., Panish, P.T. \& McEnroe, S.A. 2001: Minor element chemistry of hemo-ilmenite and magnetite in cumulate rocks from the Sokndal Region, South Rogaland, Norway. American Mineralogist 86, 1469-1476. https://doi.org/10.2138/am-2001-11-1214.

Robinson, P., Harrison, R.J., McEnroe, S.A. \& Hargraves, R.B. 2002: Lamellar magnetism in the haematite-ilmenite series as an explanation for strong remanent magnetization. Nature 418, 517520. https://doi.org/10.1038/nature00942.

Sturt, B.A. \& Ramsay, D.M. 1965: The alkaline complex of the Breivikbotn area, Sørøy, northern Norway. Universitetsforlaget, Norges geologiske undersøkelse 231, 165 pp.

Torsvik, T.H. 1998: Palaeozoic palaeogeography: a North Atlantic viewpoint. Geologiska Föreningen i Stockholm Förhandlingar 120, 109-118. https://doi.org/10.1080/11035899801202109. 